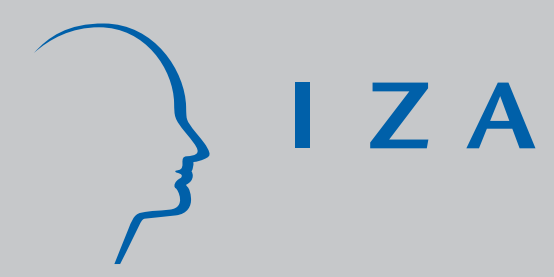

IZA DP No. 2333

Elder Parent Health and the Migration Decision of Adult Children: Evidence from Rural China

J ohn Giles

Ren Mu

September 2006 


\title{
Elder Parent Health and the Migration Decision of Adult Children: Evidence from Rural China
}

\author{
John Giles \\ Michigan State University \\ and IZA Bonn
}

Ren Mu

World Bank

Discussion Paper No. 2333

September 2006

\author{
IZA \\ P.O. Box 7240 \\ 53072 Bonn \\ Germany \\ Phone: +49-228-3894-0 \\ Fax: +49-228-3894-180 \\ E-mail: iza@iza.org
}

\begin{abstract}
Any opinions expressed here are those of the author(s) and not those of the institute. Research disseminated by IZA may include views on policy, but the institute itself takes no institutional policy positions.

The Institute for the Study of Labor (IZA) in Bonn is a local and virtual international research center and a place of communication between science, politics and business. IZA is an independent nonprofit company supported by Deutsche Post World Net. The center is associated with the University of Bonn and offers a stimulating research environment through its research networks, research support, and visitors and doctoral programs. IZA engages in (i) original and internationally competitive research in all fields of labor economics, (ii) development of policy concepts, and (iii) dissemination of research results and concepts to the interested public.
\end{abstract}

IZA Discussion Papers often represent preliminary work and are circulated to encourage discussion. Citation of such a paper should account for its provisional character. A revised version may be available directly from the author. 
IZA Discussion Paper No. 2333

September 2006

\section{ABSTRACT}

\section{Elder Parent Health and the Migration Decision of Adult Children: Evidence from Rural China*}

Recent research has shown that participation in migrant labor markets has led to substantial increases in income for families in rural China. This paper asks how participation is affected by elder parent health. We find that younger adults are less likely to work as migrants when a parent is ill. Poor elder parent health has less impact on the probability of employment as a migrant when an adult child has siblings who may be available to provide care. We also highlight the potential importance of including information on non-resident family members when studying how parent illness and elder care requirements influence the labor supply decisions of adult children.

JEL Classification: $\quad 012,015,112, \mathrm{~J} 14$

Keywords: migration, health, aging, rural China

Corresponding author:

John Giles

Department of Economics

Michigan State University

110 Marshall-Adams Hall

East Lansing, MI 48864

USA

E-mail: gilesj@msu.edu

\footnotetext{
* Supplementary materials (with additional background material and technical details) are available at http://www.msu.edu/ giles/jgrmtechappend.pdf. We gratefully acknowledge financial support from the National Science Foundation (SES-0214702), the Michigan State University Intramural Research Grants Program, the Ford Foundation (Beijing) and the Weatherhead Center for International Affairs (Academy Scholars Program) at Harvard University. This paper has benefitted from helpful discussions with Dwayne Benjamin, Loren Brandt, Emily Hannum, Xin Meng, John Strauss, Dominique van de Walle and two anonymous referees. We are grateful to Xiaohui Zhang, Liqun Cao, and Changbao Zhao from the Research Center for the Rural Economy (RCRE) at China's Ministry of Agriculture for assistance with the design and implementation of a supplemental survey to match RCRE's ongoing village and household panel surveys.
} 


\section{INTRODUCTION}

With declining fertility and increasing life expectancy, countries across the developing world face the prospect of rapidly aging populations, combined with lagging or non-existent social safety nets. Nowhere is this more true than China, home to one-fifth of the world's elderly, where lack of pensions and health insurance in rural areas is particularly acute. Support for the elderly remains the responsibility of adult children. As the population of potential caregivers continues to shrink with the appearance of attractive migrant employment opportunities, many observers have expressed concerns for the well-being of the rural elderly. ${ }^{1}$

In this paper, we examine the impact of elder parent health on the migration decision of adult children. This allows us to also address the question of how well traditional support mechanisms for the rural elderly hold up in the face of newly emerging labor market opportunities for the young. We proceed from an assumption that adult children have altruistic preferences toward elder parents, and that these preferences create incentives for children to provide time as care givers when elder parents are in poor health. In our empirical analysis, we find that presence of an ill parent, whether in the household or village, has a significant negative impact on the probability that an adult child will participate in the migrant labor market. If the extended family includes siblings, who are other potential care providers, the impact of elder parent health on the migration decision is much less pronounced.

We make use of two complementary data sources. First, we combine information from a unique longitudinal household survey spanning the period from 1986 to 2003 with a supplemental survey conducted by the authors in collaboration with researchers from the Research Center for Rural Economy (RCRE) at the Ministry of Agriculture. One advantage of the RCRE supplemental survey is that it contains detailed information about parent mortality and sibling characteristics regardless of residence location, and this allows us to study the impact of parent health on participation in migrant labor markets while avoiding potential bias driven by endogenous family decisions regarding living arrangements of the elderly. In the first set of results presented, we highlight the different conclusions that one might draw from an analysis that excludes non-resident elderly and siblings. Our results suggest that

\footnotetext{
${ }^{1}$ For example, research on China's rural elderly has found that they enjoy little in the way of retirement (see Benjamin, Brandt and Fan, 2003; Davis-Friedman, 1991; and Pang, de Brauw and Rozelle, 2004).
} 
adult children respond to elder parent needs regardless of whether they are co-residing in the same household or living in another residence within the village.

Our second data source consists of four rounds (1991, 1993, 1997 and 2000) of the China Health and Nutrition Survey (CHNS). ${ }^{2}$ One important benefit of the CHNS lies in the availability of repeat observations of multiple measures of health status that we are able to incorporate in a panel data analysis robust to potential bias from unobserved household and village characteristics, including unobserved information about non-resident family members.

The paper proceeds as follows. We first provide background information on China's demographic transition, the living arrangements of the elderly, and trends in rural-urban migration. Next, we briefly introduce a conceptual framework useful for understanding the adult child's migration decision and then proceed to discuss empirical approaches. We next present results and a final section concludes.

\section{BACKGROUND}

\section{China's Demographic Transition and the Welfare of the Elderly}

Fertility decline driven by China's population policies may ultimately lead to a breakdown of the traditional support system, but conclusions from research spanning literatures in demography and economics are not in agreement on the likeliness of this outcome. Zimmer and Kwong (2003) show that more children increase the likelihood that the elderly will receive support, but present simulation results suggesting that declines in fertility alone will not lead to collapse of family-based support for the elderly. ${ }^{3}$ Other research has suggested that financial transfers to parents respond to low income and low health status in urban areas (Cai, Giles and Meng, 2006), but that in rural areas inter-household transfers are often not observed because they take the form of labor input into family farming (Lee and Xiao,

\footnotetext{
${ }^{2}$ The CHNS is the product of collaboration between the Carolina Population Center at the University of North Carolina at Chapel Hill and the China Center for Disease Control and Prevention in Beijing. We discuss advantages and disadvantages of the CHNS in more detail in our discussion of empirical approaches below. More information on this survey can be found at the Carolina Population Center, CHNS website: http://www.cpc.unc.edu/projects/china.

${ }^{3}$ This result is consistent with simulations based on data from the 1987 Aged Population Survey which suggested that in spite of declining fertility, the rural population will be able to support elderly parents (Lin 1994).
} 
1998). ${ }^{4}$

In addition to social pressure, which may be brought to bear to enforce provision of support to the elderly, the primacy of traditional support mechanisms was codified into China's laws from early in the history of the People's Republic. The Marriage Law of 1950 states that children should support elderly parents, and the Constitution of 1954 emphasized that children have a "duty" to support parents (see World Bank, 1994; and Fang, Wang and Song, 1992). The Marriage Law of 1980 further emphasized this responsibility, and provides elderly parents with the right to sue children for support if they fail to provide assistance. ${ }^{5}$

In terms of understanding the well-being of the elderly, most research has relied on indirect evidence based on patterns of living arrangements or on analysis of labor supply and retirement decisions. Observed changes in living arrangements have been cited most frequently as reasons for concern for the well-being of the elderly. ${ }^{6}$

Proximity of adult children, rather than co-residence, may be most important for determining the well-being of China's elderly. In-kind transfers, such as supply of labor on extended family plots and provision of care, are difficult to pick up in surveys, yet such transfers often occur both within and across households. ${ }^{7}$ Within villages in rural areas, elders and adult children are typically in the same small group (a sub-village administrative unit) and live in close proximity with one another. Given increases in housing wealth

\footnotetext{
${ }^{4}$ Using other methods, Cameron and Cobb-Clark (2002) do not find evidence that transfers to parents respond to low parent income in Indonesia.

${ }^{5}$ The Marriage Law of the People's Republic of China, Section 3, Article 21 states that "Parents shall be under the obligation for the upbringing and educating of their children, and children are also under obligation to support their parents.... Where any child fails to perform his or her obligations, parents who are unable to work or who are living a difficult life shall be entitled to ask their child to pay aliments (funds necessary to support basic housing and nourishment)." (Authors' translation from 'Decision on Amending the Marriage Law of the People's Republic of China made at the 21st meeting of the Standing Committee of the Ninth National People's Congress', April 28, 2001).

${ }^{6}$ Selden (1993) concludes that a transition to the nuclear family imposes a heavy price on the rural elderly. Benjamin, Brandt and Rozelle (2000) note that in Northern China over 85 percent of elderly lived in extended households in 1935, but that this figure had dropped to just over 60 percent by 1995. Living arrangements are thought to be important for elderly support across East Asia, including Cambodia (Zimmer and Kim, 2002), Thailand (Knodel and Debavalya, 1997), and Viet Nam (Anh et al, 1997). In China, the decline in co-residence is evident in both the urban and rural samples of the CHNS. Figure S.2 of the supplementary appendix shows that in 70 percent of rural elderly lived with an adult child in 1991, but by 2000 this share had fallen to 60 percent.

${ }^{7}$ In a study of elder support in Shanghai and Tianjin, for example, Bian et al (1998) found that nonresident sons and daughters frequently live near elderly parents and provide regular non-financial assistance to them.
} 
accumulated in rural areas since the mid-1980s, the trend toward nuclear families may well signal a wealth effect independent of the traditional value of providing support and care to elder parents. A more important concern may be the proximity of adult children, and not whether they co-reside. Figure 1 summarizes the living arrangements by age cohort from the 2004 RCRE supplemental survey (discussed below), and includes information on children living within the same village as their elders. While co-residence with adult children was only around 60 percent among those aged 60 to 70, more than half the elderly living alone or with a spouse in this age range had at least one adult child living in the village. This suggests that while co-residence was well below levels of the 1930s, adult children were still potentially available to provide care.

\section{Rural-Urban Migration in China}

During the 1990s, China's labor market experienced dramatic growth in the volume of rural migrants moving to urban areas for employment. Estimates using the one percent sample from the 1990 and 2000 rounds of the Population Census and the 1995 one percent population survey show that the inter-county migrant population grew from just over 20 million in 1990 to 45 million in 1995 and 79 million by 2000 (Liang and Ma, 2004). Surveys conducted by the National Bureau of Statistics (NBS) and the Ministry of Agriculture include more detailed retrospective information on past short-term migration, and suggest even higher levels of labor migration than those reported in the census (Cai, Park and Zhao, 2006).

With respect to well-being of the elderly, however, it is likely that the decision of adult children to participate in migrant labor markets places greater pressure on the rural elderly to continue working. Lack of a pension system for the rural elderly is compounded by a system of land ownership that places families at risk of losing control over land that is not farmed, and that leaves elderly with few sources of non-labor income in their retirement. Furthermore, given the returns to migrant employment, it is likely that healthy farmers over 55 years of age choose to continue work in agriculture in order to allow adult children to increase family income through employment outside the village.

Once elders become infirm, however, it is likely that adult children will find a way to provide some type of care. Often this will mean that at least one adult child will either 
return to the village, or decide not to participate in the migrant labor market. Anecdotal accounts suggest that migrants face pressure to return to the countryside to fulfill obligations to parents who are too ill to care for themselves. ${ }^{8}$ The potential opportunity cost of caring for elder parents is clear, however, from descriptive evidence on conflict among siblings over decisions related to elder care. In 11 of the 55 RCRE villages from which household survey data are drawn for this paper, village leaders reported such disputes were either the first or second most important cause of conflict within the village. ${ }^{9}$ As we will see below, the presence of siblings reduces the impact of poor elder parent health on migration decisions. But it is also likely that siblings "bargaining" over who will meet their traditional responsibility recognize the opportunity costs of caring for parents.

\section{PARENT HEALTH AND THE DECISION TO WORK AS A MIGRANT ${ }^{10}$}

\section{A Simple Conceptual Framework}

An adult child is assumed to care about both parent well-being and to have an interest in maximizing his (or her) own income. With higher wages available through migrant employment, young adults may prefer to work outside their home villages. When a parent's health status is good enough that he (or she) does not require instrumental care, then parent well-being does not place restrictions on where adult children choose to find employment. When a parent is ill and requires assistance, however, an adult child is faced with the choice of hiring someone to care for his (or her) parent, relying on a family member for assistance, or returning to the village to provide care himself (or herself). Markets for provision of instrumental care to the elderly are not well-developed in rural China (the "price" at which unrelated caregivers could be hired may be prohibitively high), and thus an adult child who cares about the well-being of his (her) parent will be less likely to participate in the migrant

\footnotetext{
${ }^{8}$ Pang et al (2004), for example, cite an interview with a migrant couple who stated that they had to return to their home village from higher wage jobs as migrants to care for an elderly parent.

${ }^{9}$ Conflict among siblings over care for the elderly was the third most important source of conflict in the 55 RCRE villages from which our data are drawn. This places conflict over elder care just behind disputes over land boundaries and water rights, which are common across the developing world. The Chinese term we used for conflict in the survey, jiufen, implies a dispute significant enough to bring in police or other authorities from outside the village.

${ }^{10}$ For interested readers, a more technical exposition of the adult child's decision is presented in the supplementary appendix available at http://
} 
labor market. The effect of parent illness on migrant employment may be less pronounced if the adult child has siblings who are available as affordable care providers.

\section{Empirical Approaches}

As outlined in the conceptual framework above, we expect to find that migration patterns differ with the health status of parents. To estimate the impact of parent health on the migration decision of individual $i$ in time $t$, one might choose a reduced form binary choice model:

$$
M I G_{i t}=\alpha H_{i t}^{P}+\mathbf{Z}_{i t}^{\prime} \beta_{1}+\mathbf{X}_{i t}^{\prime} \beta_{2}+\mathbf{V}_{j}+\mathbf{Y}_{p \times t}+\mathbf{u}_{i}+\epsilon_{i t}
$$

where $M I G_{i t}$ is a binary variable equal to one if individual $i$ participates in the migrant labor market in year $t, H_{i t}^{P}$ is the health status of a parent (or parents) of individual $i, \mathbf{Z}_{i t}$ and $\mathbf{X}_{i t}$ are vectors of household and individual characteristics, respectively, that affect individual $i$ 's preferences or ability to participate in the migrant market. Village fixed effects, $\mathbf{V}_{j}$, control for proximity to cities and other fixed factors that likely influence the cost of migrating. A vector of province-year dummy variables, $\mathbf{Y}_{p \times t}$, control for both fixed province effects and time-varying macroeconomic shocks that affect demand for labor and temporary differences in the legal ease of migrating. Next, one might worry about unobservable factors, $\mathbf{u}_{i}$, that influence the migration decision, and an error term.

The objective of our analysis is to arrive at an unbiased estimate of $\alpha$, which picks up the impact of parent health on the migration decision. From this specification, it is clear that four potential problems should concern us: simultaneity bias, omitted variable bias, bias due to random error in the measurement of parent health status, and selection of elderly parents into the household. With respect to simultaneity bias, some household and individual characteristics, $\mathbf{Z}_{i t}$ and $\mathbf{X}_{i t}$ (such as marital status, school enrollment and fertility decisions), may reflect decisions made jointly with the migration decision, $M I G_{i t}$. Solutions to this problem require care in choice of covariates, and as an extra precaution, use of covariates that are, at the least, predetermined at time $t$. Thus, one might consider 
regressing the period $t$ decision on period $t-1$ household and individual characteristics, or:

$$
M I G_{i t}=\alpha H_{i t-1}^{P}+\mathbf{Z}_{i t-1}^{\prime} \beta_{1}+\mathbf{X}_{i t-1}^{\prime} \beta_{2}+\mathbf{V}_{j}+\mathbf{Y}_{p \times t}+\mathbf{u}_{i}+\epsilon_{i t}
$$

Unobservable factors correlated with peristent poor health of parents and the migration decision pose a more serious concern, and using predetermined household characteristics alone will not solve these problems. Several sources of bias may be present if we estimate (2) using pooled cross sections from typical household survey data. First, ability to observe elder parent health reflects a potentially endogenous decision of the household and family: the elder parent's presence in the household may reflect a decision to "employ" a grandparent as a provider of child-rearing services to the adult child's family. This unobserved decision behind selection of an elderly person into the household may facilitate participation in migrant labor markets and will be systematically related to the adult child's migration decision. Alternatively, the adult child may be living in a parent's household because he, or she, has not yet married and established a family, or may not have saved sufficient resources to set up a separate household. In this case, the migration and co-residence decision may be systematically related to credit constraints faced by the adult child, which may be related to ability to migrate. Finally, an elder parent's residence in the household may reflect the outcome of a bargaining process among siblings, with the household choosing to care for an ill parent making an implicit decision to reduce participation in the migrant labor market.

Omitted variable bias may be serious if the adult child's non-resident siblings are unobserved. Ability to "hire" a sibling to care for elder parents may be important for understanding the migration decision. When using typical household survey data, the researcher does not have information about siblings, or children, who are not residing in the household. Number of siblings, who are either potential caregivers or potential recipients of parent labor, will be systematically related to whether or not we observe an elder parent living in the household. Further, number of siblings may be systematically related to the decision to migrate because larger extended families have more funds available to finance a new migrant. Alternatively, larger extended families may be engaged in more extensive family business 
activities in which an adult child could find local employment. We cannot sign the bias $a$ priori, but such unobservables related to the extended family will be correlated with both the living arrangement decision that brings an elderly person into the household, and the decision to participate in the migrant labor market.

Finally, from a typical household survey it is not certain that we know whether parents are still alive if they do not live in the household, and if they are not in the household, we may not be able to come up with a proxy for parent health status. Given that declines in coresidence with adult children may reflect increased wealth and be independent of changes in support provided to parents, we may underestimate the impact of parent health on migration if we do not have information on non-resident parents.

We use two approaches to deal with these unobservables. First, we make use of unique survey data that allows us to include what would normally be omitted variables related to parents and extended family members who are not residing in the household. Second, we estimate first-differenced models that sweep out unobserved effects using four waves of the China Health and Nutrition Survey (CHNS). Both of these approaches take us a long way toward solving biases related to unobserved heterogeneity, and each approach will have both strengths and weaknesses. Below, we outline our identification strategy for each approach and the data source used and then discuss results in the following section.

\section{Identification Using the Research Center for Rural Economy (RCRE) Supplemental and Household Surveys}

The first set of analyses that we present use supplemental survey data collected through collaboration with researchers at the Research Center for Rural Economy (RCRE) at China's Ministry of Agriculture. All 3999 households in four provinces of the 2003 wave of RCRE's panel were enumerated, allowing us to match villages and households in 2004 with a historical panel of households that RCRE surveyed annually from 1986 through 2003. The original sample of RCRE villages and households was drawn in 1986. In each province, counties in the upper, middle and lower income terciles were selected, from which a village was then randomly chosen. Depending on village size, between 40 and 120 households were randomly 
surveyed in each village. ${ }^{11}$ During multiple pre-test exercises for the supplemental survey, we found that recall on family member residence locations and migration history was salient in the minds of respondent households if enumerators worked backwards carefully to 1995. Thus, we examine the impact of parent health on migration from 1995 onward.

The supplemental survey has several unique features that are important for our analysis. First, we know the education level, birth year, current occupations, work and migration history, parent and sibling characteristics and residence location for the household head, spouse and all adult children of households in the survey. ${ }^{12}$ Furthermore, we know geographic location of parents and siblings for all individuals as of 2003, and the year of death of parents and siblings who have passed away through October 2004. These data allow us to estimate a version of (2) in which parents, parent health and sibling information are introduced at the level of the family, not the household. Extensive parent and sibling information allow us to estimate the impact of parent health on migration independent of unobserved factors affecting parent and sibling selection into the household. We estimate:

$$
\begin{aligned}
M I G_{i t} & =\mathbf{H}_{i t-1}^{P \prime} \alpha_{1}+\left(s_{i t-1} \cdot \mathbf{H}_{i t-1}^{P}\right)^{\prime} \alpha_{2}+\alpha_{3} P A R_{i t-1}+\alpha_{4} s_{i t-1}+\mathbf{Z}_{i t-1}^{\prime} \beta_{1} \\
& +\mathbf{X}_{i t-1}^{\prime} \beta_{2}+\mathbf{Y}_{v \times t}+\mathbf{u}_{i}+\epsilon_{i t}
\end{aligned}
$$

Our dependent variable in (3) takes a value of one if an adult child, head or spouse decides to participate in the migrant labor market during year $t$. We look exclusively at individuals who leave the household and move to a location outside of the home county for the purpose of employment. Migrants include both individuals who may commute back to the household on

\footnotetext{
${ }^{11}$ A detailed discussion of a larger nine-province sample from the RCRE panel dataset, including discussions of survey protocol, sampling, attrition, and comparisons with other data sources from rural China, can be found in the data appendix of Benjamin, Brandt and Giles (2005). This paper makes use of village and household data from the four provinces where the authors conducted a follow-up household survey, and include Anhui, Henan, Jiangsu and Shanxi.

${ }^{12} \mathrm{~A}$ detailed breakdown by family relationship of the sample used in our estimation is shown in Table S.1 of the supplementary materials (http:// ). As a consequence of the enumeration strategy followed for non-resident family members, we do not have data sufficient to examine the importance of daughters-in-law or marital status on migration decisions. These potentially important effects will be highlighted in our discussion of results below.
} 
weekends, and individuals who spend nearly the entire year away from the household. $\mathbf{H}_{i t-1}^{P}$ are indicators for parent health status, $s_{i t-1}$ is the number of siblings alive, and $P A R_{i t-1}$ is the number of parents still alive at $t-1$. In our preferred model, all three of these variables are at the family level and are measured independently of residence in the household. The coefficient vector $\alpha_{1}$ picks up the effect of parent health, regardless of parent location, on the adult child migration decision and we expect that poor health will be associated with a lower probability of participating in the migrant labor market. The availability of siblings will lower the cost of hiring care for ill parents, and thus we would expect the coefficient vector $\alpha_{2}$ to carry a sign opposite to the sign on $\alpha_{1}$, reflecting a reduction in the effect of parent illness on the migration decision with an increase in the number of siblings. We also include a vector of village-year fixed effects $\mathbf{Y}_{v \times t}$ that controls for both village fixed effects (such as location, which influences the cost of migration and proximity to health care) and shocks to the village that may affect both elder parent health and the ability or desire to migrate. $^{13}$

Parent health status: subsequent mortality. We use information on parent subsequent mortality as our measure of parent's current health status. Death is often preceded by a considerable period of illness or infirmity in which an individual is unable to work and may require care. ${ }^{14}$ We use three indicators to examine the relationship between parent health and migration in period $t$ : parent died in year $t$, year $t+1$ and year $t+2$, respectively. ${ }^{15}$ Parent mortality is useful as an indicator because it is salient in the minds of respondents regardless of whether or not the parent resided in the household, and thus it is straightforward to recover from a retrospective follow-up survey. Figure 2 shows plots of the bivariate relationship between the share of an age cohort working as a migrant and age by subsequent

\footnotetext{
${ }^{13}$ A drought, for example, may lower household income sufficiently to reduce a family's ability to provide sufficient nutrition to all family members and create incentives to migrate. Alternatively, if migration is costly, a local weather shock may make it more difficult for some households to support sending a family member to work as a migrant.

${ }^{14}$ Early research on retirement behavior in the US favored subsequent mortality experience over selfreported health status as a health status indicator. See, for example, Anderson and Burkhauser (1985), Hurd and Boskin (1984) and Parsons (1980).

${ }^{15}$ We experimented with longer leads of parent mortality experience, but find that effects are not significant for leads greater than two and, from a practical estimation standpoint, longer leads require that we lose more observations.
} 
parent mortality. For adult cohorts over age 25, parent death one year and two years in the future is associated with lower migration rates for both men and women. For younger cohorts, parent death is more likely to have been a surprise and not preceded by a lengthy period of illness.

Individual characteristics. We include several characteristics intended to pick up heterogeneity across individuals in the returns that can be earned locally and in the migrant labor market. Individual educational attainment in the year prior to the decision to participate in the migrant labor market is included as a measure of human capital. Educational attainment is represented by two variables: completion of middle school (eight years of formal education in villages with five year elementary schools and nine years of formal education in villages with six year elementary schools) and completion of high school (eleven or twelve years of education depending on the duration of elementary education in the area). The educational attainment of parents (completion of middle school and high school) is included to control for dimensions of unobserved ability picked up from parents, and for family preferences regarding enrollment in high school and occupational choice. Finally, age and age-squared are included to control for life-cycle effects that may influence the decision to participate in the migrant labor market.

Household characteristics. We merge two variables from annual rounds of the RCRE panel household survey on to the supplemental survey and use them to control for the attractiveness and ability to participate in the migrant labor market. Lagged household land per capita controls for factors affecting the ability to earn income from farming, and by implication, differences across households in the potential increase in income from participation in the migrant market. We include the lag of log household consumption per capita as a control for household wealth, which influences both ability and desirability of participating in the migrant market. Finally, from retrospective information in the RCRE Supplemental survey on past members of the household, we include a vector of household demographic characteristics. The vector of household demographic characteristics (shown in Appendix Table A.1) excludes elderly parents and siblings whose information we employ in our models 
at the family (not household) level.

The error term. After we control for the characteristics of parents and siblings regardless of residence, we assume that there are no other important omitted variables correlated with parent health and the migration decision that could bias our results. ${ }^{16}$ Our preferred model presents cross-section results that include (normally omitted) variables related to siblings and parents, and these results will not be influenced by biases introduced through selection of elder parents or siblings into the household.

\section{Identification Using the China Health and Nutrition Survey (CHNS)}

The CHNS and the Rural Sample. The China Health and Nutrition Survey (CHNS) is conducted through a joint effort of the Carolina Population Center at the University of North Carolina at Chapel (in the US), and the National Institute for Nutrition and Food Safety and the China Center for Disease Control and Prevention (in China). The CHNS is a longitudinal survey that covers urban and rural areas of nine provinces that vary substantially in geography, economic development and public resources. ${ }^{17}$ While five waves of the survey (1989, 1991, 1993, 1997 and 2000) were available at the time that we conducted our research, the 1989 health data was only collected from pre-school children and adults aged 20 to 45 . We thus use data from the four waves spanning 1991 to $2000 .^{18}$

For our study we use households that we determined to be rural in 1991. Surveyed clusters in the CHNS change their designation over time and the designation is based not on household activities but on the legal residential registration category of residents. We

\footnotetext{
${ }^{16}$ At first blush, it might appear appropriate to control for remaining unobservables using a first-differenced specification. If we did so, we would lose interesting information on the impact of siblings, which vary little in the panel. Further, much of the data used in our analyses comes from retrospective information in the supplemental survey. While we construct the data source used in our estimation in panel form, firstdifferencing with retrospective information does not control for unobservable effects if they are systematically related to household specific errors in recall.

${ }^{17} \mathrm{~A}$ multi-stage, random cluster approach was used to draw the sample. Counties in the nine provinces were stratified by income (low, middle, and high) and a weighted sampling scheme was used to randomly select four counties (one in low, two in middle and one in high income counties) from each province. In addition, the provincial capital and a lower-income cities were selected. Villages and townships within the counties and urban and suburban neighborhoods within the cities were selected randomly.

${ }^{18}$ In order to link individuals to form a longitudinal panel, we first used the Master ID file provided by the Carolina Population Center. This file includes all previous id numbers for individuals. In addition to the Master ID file, we used available age and gender information to verify matches across years and to correct cases in which the Master ID file led to an obvious mis-match of individuals over time.
} 
work from the subsample of households drawn from survey clusters in which 20 percent or more of individuals surveyed designated that their primary activity was farming in $1991 .^{19}$ The summary statistics for individual and household characteristics and number of male and female observations for the four rounds of the survey are shown in Appendix Table A.2.

Measures of Health Status. One benefit of the CHNS is that it contains repeat observations on different measures of health status. This is particularly valuable for the difficult task of studying the effects of elder parent health. At the same time, survey data on health status are not always straightforward to use in econometric estimation. Health is multi-dimensional and measures of health in socioeconomic surveys each isolate only a few dimensions of health status. Moreover, health measures are often reported with considerable error, and worse, the respondent's socioeconomic status or beliefs may be correlated with use of health facilities or access to information about health, and thus lead to considerable bias in reporting of health outcomes. Below, we first briefly review the measures of health status from the CHNS that we use in our analysis, and discuss particular concerns with each measure that must be dealt with in order to credibly identify the impact of elderly health on migration decisions. ${ }^{20}$

Self-Reported Health Status (SRHS) is viewed by some to be the best composite indicator of health because SRHS performs well as a predictor of subsequent mortality. ${ }^{21}$ On the other hand, SRHS is subject to several important sources of bias that may be systematically related to labor supply, to household socioeconomic status and to family decisions about activities such as participation in migrant employment. Bias may arise because "good" health may not mean the same thing to all people. Perceptions of one's health, or of a household member's health, may be related to values, beliefs and information, all of which may be related to socioeconomic characteristics or concurrent or prior use of health care facilities. ${ }^{22}$

\footnotetext{
${ }^{19}$ Our results are robust to other definitions of rural and to following the CHNS definition of rural. We believe that using a definition in 1991 is important, however, because this limits the scope for systematic attrition bias as households in some regions experience a change in legal classification.

${ }^{20} \mathrm{~A}$ more detailed discussion of these measures in the developing country context can be found in Strauss and Thomas (1998). In Appendix Table A.2 we provide summary statistics of important CHNS variables used in our analyses.

${ }^{21}$ Benjamin et al (2003) demonstrate that self-reported health status does a good job of predicting subsequent mortality in the CHNS data used in this paper.

${ }^{22}$ Research from the RAND Health Insurance Experiment suggests that while health may improve with
} 
Further, justification bias may arise if an individual's decision about participation in the labor market is related to feelings about own health or the health of an elderly parent. Finally, measurement error may arise because SRHS is typically measured on a discrete scale and only imperfectly captures fine gradations in health status. Using a unique data source that allows them to decompose errors in SRHS, Baker, Stabile and Deri (2004) found that random measurement error accounted for as much as 80 percent of the error in the self-reported health measures in the Canadian survey used in their analysis.

The CHNS question on SRHS asks respondents to rate their health relative to other people their age, and then responses are coded on a scale of one (excellent) to four (poor). When we make use of this variable below, we transform the SRHS of all elderly into a discrete indicator of poor health, H34, which equals one when one or more elderly residents have fair (three) or poor (four) health. ${ }^{23}$ Keeping Baker et al's findings in mind, we are concerned with error in the measure of the presence of an elder in poor health.

Body Mass Index (BMI) is the ratio of weight (in kilograms) to height (in meters) squared and provides an anthropometric measure of physical health. Extremely low and high BMI are each associated with higher adult mortality. High levels of SRHS are associated with poor health in the CHNS, and we see a familiar $U$-shaped curve in which low BMI is associated with lower health status, and health status appears to worsen, albeit slowly, as BMI increases beyond $30 .{ }^{24}$ Since BMI has an important relationship to SRHS and to labor supply decisions when very high or very low, we follow Benjamin et al (2003) and use it to construct two discrete measures: High BMI and Low BMI, which equal one when an individual's BMI is in the highest or lowest 20 percent of the annual BMI distribution, respectively. ${ }^{25}$

use of health facilities, self-reported health status may actually decline as those expanding utilization of health care facilities receive more accurate information about actual health status (Newhouse et al, 1993).

${ }^{23}$ One solution to the pitfalls of using SRHS would be to construct indices from activities of daily living (ADLs) and information on physical functioning. Unfortunately this information was not available until the 1993 survey year.

${ }^{24}$ Costa (1996) shows a plot of the relationship between BMI and self-reported health in her historical study of older male labor force participation. Figure S.5 in the supplementary appendix shows the same relationship as that produced by Costa between self-reported health status of the elderly and the BMI of elderly in the CHNS.

${ }^{25}$ Our analytical results are robust to constructing High BMI and Low BMI using fixed cut-offs and defining Low BMI as less than 18.5 (underweight) and High BMI as greater than 25 (overweight). 


\section{Empirical Approaches Using the CHNS}

In order to achieve robust and consistent estimates of the effect of elder health on migration behavior in equation (2) above, we must control for omitted variable bias and measurement error bias. In order to be comparable with the RCRE-based analyses, we would like to use a single composite measure of elderly health. For this reason, presence of an elderly resident with poor health $(H 34=1)$ has distinct advantages, but a serious disadvantage remains in that it will be related to socioeconomic status, culture and preferences that will be unobserved, but are likely to be correlated with family-specific benchmarks for judging health status. Under the assumption that unobservables are not changing much between two time periods, our preferred model uses first-differences to sweep out these effects. ${ }^{26}$ The dependent variable, $M I G_{i t}$, is equal to one if an individual migrated out of the household between periods $t-1$ and $t$, zero if no migration occurred and negative one if a family member moved back to the household. ${ }^{27}$ The first-differenced specification is:

$$
\begin{aligned}
\Delta M I G_{i t} & =\alpha_{1} \Delta H_{i t-1}^{E}+\alpha_{2} \Delta H_{i t-1}^{i}+\alpha_{3} \Delta \operatorname{Low} B M I_{i t-1}^{i}+\alpha_{4} \Delta \operatorname{High} B M I_{i t-1}^{i} \\
& +\Delta \mathbf{Z}_{i t-1}^{\prime} \beta_{1}+\Delta \mathbf{X}_{i t-1}^{\prime} \beta_{2}+\mathbf{Y}_{p \times t}+v_{i t}
\end{aligned}
$$

where $\Delta H_{i t-1}^{E}$ is the change in the incidence of an elderly household member reporting fair or poor health (H34). Three measures of own health status, $\Delta H_{i t-1}^{i}, \Delta \operatorname{Low} B M I_{i t-1}^{i}$,

\footnotetext{
${ }^{26}$ This strong assumption is made here, as elsewhere in the literature (Benjamin et al 2003) under the belief that the stagnation in provision of health care in China's rural areas over this period makes it unlikely that information about what constitutes good health status is changing in a way that is systematically related to migration behavior.

${ }^{27}$ If an individual who was in a previous round of the CHNS is not in the current round of the survey, a question is asked regarding the location of this individual. We consider any individual who has left the home county between period $t$ and $t-1$ to be a migrant. We are unable to differentiate migration for work from migration for marriage or college enrollment. We assume that most attrition through marriage may involve leaving home villages, but seldom lead to migration out of home counties. Further, few rural residents actually attend college (high schools are located within home counties). Nonetheless, it is important to consider the nature of the bias that we may observe if these assumptions are incorrect. If parent health status does not affect the adult child's marriage or college enrollment decisions, then inclusion of migrants leaving for marriage or school would lead to an underestimate of the impact of parent health on work-related migration. If parent health status also affects marriage or college enrollment decisions, however, then the sign of the bias cannot determined. A child may get married sooner so that an infirm elder will know that his or her child has set up a family, or alternatively, marriage may be delayed to facilitate provision of care.
} 
$\triangle \operatorname{High} B M I_{i t-1}^{i}$, are included directly to control for the possibility that changes in own health status are correlated with changes in elder health status. ${ }^{28}$ Change in household and individual characteristics, $\Delta \mathbf{Z}_{i t-1}$ and $\Delta \mathbf{X}_{i t-1}$ control for factors affecting household preferences, and $\mathbf{Y}_{p \times t}$ are province-year dummy variables that control for provincial level growth trends and time-varying macroeconomic shocks. Unobserved village and household fixed effects are eliminated through first-differencing.

While first-differencing solves problems created by omitted variable bias, random measurement error bias in the differenced $\Delta H_{i t-1}^{E}$ will lead to attenuation of $\alpha_{1}$. We use the change in lag shares of the elderly with high and low BMI as instruments for $\Delta H_{i t-1}^{E}$ to correct for classical measurement error bias. It is important to emphasize that one may still be concerned that some other unobserved factors may be driving both the lagged change in parent health and the migration decision. If such an unobserved factor is present, then the coefficient $\alpha_{1}$ may yet suffer from endogeneity bias. While we do not have valid instruments to control for such endogeneity, we perform an over-identification test to determine whether our preferred instrumental variables estimate suffers from obvious endogeneity bias. ${ }^{29}$

\section{RESULTS}

\section{Estimates Using the RCRE Supplemental and Household Surveys}

To assess the extent and direction of bias that may be introduced when using observed information on household members alone, we first estimate model (3) excluding information on parents and siblings not living in households. Results for this specification are shown for men in columns (1) and (2) of Table 1 and in columns (5) and (6) for women. We observe negative coefficients of $-0.048,-0.076$ and -0.071 on indicators of parent death in years $t$, $t+1$ and year $t+2$, respectively, suggesting that when information on parents outside the household is excluded we observe a negative relationship between parent health and

\footnotetext{
${ }^{28}$ If this were the case, then elder health status may be picking up the effect of own health status on the migration decision.

${ }^{29}$ Readers who are unfamiliar with the use of instrumental variables to correct for problems associated with random measurement error are encouraged to consult Chapter 15 of Wooldridge (2006) for an accessible and intuitive exposition. An over-identification test assesses whether residuals from the second stage regression are systematically related to instruments used in the first stage model. If such a systematic relationship exists, we would be more concerned about endogeneity bias.
} 
probability that male adult children will be employed as migrants. ${ }^{30}$ We observe a negative coefficient on number of parents alive (and living in the household) and positive coefficients on number of siblings (also living in the household). Parents living in the household may be associated with care or other forms of economic assistance provided by adult children that dominate potential elder role in child care. The positive coefficient on siblings in the household may reflect an endogenous decision to maintain a larger household capable of diversifying across a range of activities, one of which may include participation in the migrant labor market.

Models with interaction of siblings and elder parent health variables in columns (2) and (6) do not yield statistically significant coefficients. Coefficients on parent health (subsequent mortality variables) do not differ significantly from those in the model without interactions, while coefficients on interactions with siblings do not suggest that siblings provide care sufficient to allow for migration. Finally, we observe no significant effects of parent health on the migration behavior of women.

Inclusion of information on siblings and parents regardless of residence in the household suggests that observing only household residents may indeed introduce significant bias. We show results from our preferred models that include extended family information for men in columns (3) and (4) of Table 1, and in columns (7) and (8) for women. The full model for men, shown in column (4), suggests a stronger negative impact of parent illness on the migration behavior of men than when information on non-resident parents and siblings is excluded. Excluding both the existence of parents and information on parent health status leads to underestimation of the effects of elder illness on migration decisions of individuals with few siblings. We find a significant 15 to 16 percent decrease in the probability of migrating when a parent is ill and the adult child has no siblings. The significant parent health-sibling interaction terms suggest that existence of siblings available to provide care will reduce the negative effects of elder parent illness on the ability to migrate by 2.7 to 3.1 percent per sibling. These results indicate that the effects of parent health on migration behavior will be under-appreciated if we fail to consider the existence of sick parents not

\footnotetext{
${ }^{30}$ Note that only the coefficient on parent death in year $t+1$ is significant at the 5 th percentile.
} 
residing in the household, and further, are consistent with adult children whose labor supply decisions are responsive to parent illness regardless of whether or not parents reside in the household.

It is also interesting to note that the effect of siblings on migration switches from positive and significant to negative and significant once we consider number of siblings regardless of membership in the household. Presence of siblings may indeed be related to an endogenous decision to maintain a larger more diversified household. ${ }^{31}$ The negative relationship between number of siblings and migration in family-level regressions suggests that size of the local family network may be systematically related to local opportunities and dominate the effects of family size on ability to participate in the migrant labor market.

Given that women are often primary care providers in rural China, it may seem surprising to find that male migration is influenced more strongly by elder parent illness than female migration. First, it is important to remember that women have somewhat lower migration rates than men (as evident in Figure 2), particularly when they are over 30, and with a smaller sample of migrants we will be less likely to observe an effect. More importantly, a woman's responsibility to elders will likely switch from her own parents to her spouses parents upon marriage, and thus we may not observe a significant response to own parent illness. ${ }^{32}$ Ideally, one should examine a daughter-in-law effect on migration, but we are unable to perform this exercise without introducing considerable selection bias because the RCRE supplement failed to record the year of marriage for children and siblings living outside the household as of $2004 .^{33}$ When interpretting the sensitivity of male migration to elder parent illness, it is thus important to keep in mind that migration behavior in response to parent illness may be systematically related to multiple motives of the adult son and daughter-in-law. These motives may include provision of instrumental care (perhaps by the daugher-in-law) or supply

\footnotetext{
${ }^{31}$ Alternatively, siblings may be more likely to reside in the household when both the individual and the sibling are young. In this case, a sibling who is still a legal resident may be a source of information about migrant opportunities and thus lead to a positive association between sibling presence and migration.

${ }^{32}$ However, it is notable that when we group siblings separately by gender, point estimates suggest that existence of a sister has a much stronger effect on reducing the likelihood that an adult son will return home to when an elder parent is ill. This suggests that women who reside in the same villages as their elderly parents continue to serve as care providers even though they have moved into their spouse's household (see Table S.2 of the supplementary appendix for more detail).

${ }^{33}$ In the selected sample, we do not observe a daughter-in-law affect.
} 
of labor to household managed plots and other household activities. ${ }^{34}$

\section{Estimates Using the CHNS}

The first stage. In Table 2 we present results of first-stage regressions of change in the presence of an ill elderly resident on change in share of elderly with low and high BMI, and all other regressors in the main model. The estimated coefficients suggest a sufficiently strong relationship between these measures of elder health status and the change in share of elderly in poor health to function as valid instruments to correct for the effects of random measurement error. F-statistics on these two variables are 15.11 for men and 7.47 for women with F-probabilities below one percent. The model also controls for changes in household structure between $t-2$ and $t-1$ and this is important because the presence of elderly members who are ill will change mechanically if elder parents move into or out of the household.

The impact of elder health on the migration decision. In Table 3 , we show the ordinary least squares (OLS), first-differenced (FD) and first-differenced instrumental variables (FDIV) models of the impact of lagged elder health on subsequent migration behavior of adult children. The coefficient on elderly member in fair or poor health is negative as one might expect in both the OLS and first-differenced models. Keeping in mind that the first-differenced models sweep out the effects of fixed unobservables, such as unobserved differences across households in what they consider to be fair or poor health, these models will be preferred to the OLS models. Classical (random) measurement error, however, will introduce more serious attenuation bias in first-differenced models, thus leading to coefficient estimates that are biased toward zero. When we instrument for presence of elderly members in fair or poor health, in columns (3) and (6), we find that the coefficient estimates increase in magnitude as one would expect if the FD results suffer from attenuation bias as a result of measurement error. We find that presence of an elder in fair or poor health reduces the probability of subsequent participation in migrant labor markets by 26 percent for men (the coefficient estimate is -0.260$).{ }^{35}$

\footnotetext{
${ }^{34}$ We also examined whether presence of grandchildren under care of grandparents affected migration of parents upon grandparent illness. We did not find a separate grandchild effect.

${ }^{35}$ The coefficient estimate for women carries a negative sign but is statistically insignificant in the first-
} 
In terms of understanding the importance of possible selection effects, reflection on the RCRE-based results suggests that selection of an elderly person into the household in our CHNS-based estimates is not necessarily leading us to overestimate the negative effect of poor elder parent health on the migration behavior of younger adults. Indeed, our exercise with models excluding and including extended family members with the RCRE data suggest that omitted information on both elder parents and siblings not residing in the household may lead us to underestimate the effect of parent health on migration decisions.

\section{CONCLUSIONS}

Using two different data sources and complementary estimation strategies, we find that the ill health of elder parents reduces the probability that adult male children will participate in the migrant labor market. Our findings have significant implications for our understanding of how well traditional support mechanisms are functioning and the role that living arrangements play in facilitating support. While it is likely that both the demographic transition and new labor market opportunities are putting traditional family-based support mechanisms under considerable strain, it appears that young rural adults continue to respond to traditional responsibilities. Changes in living arrangements do not necessarily indicate a decline in the willingness to care for parents, and this is evident in the stronger adult child response to parent illness when we include information on the health status of non-resident parents.

Our results may have important policy implications for the development of social safety nets in rural China. In the absence of a social safety net, infirmity of the elderly may restrict the income earning choices of adult children. To be sure, the absence of children from the village before an illness and supply of labor to agricultural production by the elderly may hasten the deterioration in health that leads to infirmity. Lack of pensions, lack of insurance for health treatment and lack of accumulated assets, all of which restrict the ability of the elderly to retire, are plausibly related to the earlier onset of a serious illness that may force adult children to forgo income earning opportunities in urban areas. As stressed elsewhere

differenced instrumental variables models. As a robustness check we also estimated models in which Low $\mathrm{BMI}$ is below a fixed value of 18.5 and High BMI is above 25. Use of these definitions did not yield qualitative differences in the effect of parent illness on migration. Results are available from the authors upon request. 
(e.g. Benjamin et al, 2000; and Benjamin et al 2003), improved safety nets and secure tradable property rights over land may have significant beneficial effects for elderly welfare in China's rural areas, but these benefits may not be restricted to the elderly alone. Results from our analyses in this paper suggest that labor supply decisions of adult children may also be influenced by factors affecting the health status and longevity of China's elderly. Further research is warranted to determine whether introduction of safety nets or the appearance of land rental markets might facilitate reduced labor supply of the elderly and lower incidence of illness.

\section{REFERENCES}

Anderson, Kathryn H. and Richard V. Burkhauser. 1985. "The Retirement-Health Nexus: A New Measure of an Old Puzzle," Journal of Human Resources v20, n3 (Summer 1985): 315-30.

Anh, Truong Si, Bui The Cuong, Daniel Goodkind, and John Knodel. 1997. "Living Arrangements, Patrilinearity and Sources of Support among Elderly Vietnamese," Asia-Pacific Population Journal 12(4): 69-88.

Baker, Michael, Mark Stabile and Catherine Deri. 2004. "What Do Self-Reported, Objective, Measures of Health Measure?" Journal of Human Resources v39, n4 (Fall 2004): 1067-93.

Benjamin, Dwayne, Loren Brandt and Jia-Zheung Fan. 2003. "Health and Labor Supply of the Elderly in Rural China," manuscript, Department of Economics, University of Toronto

Benjamin, Dwayne, Loren Brandt and John Giles. 2005. "The Evolution of Income Inequality in Rural China," Economic Development and Cultural Change 53(4): 769-824.

Benjamin, Dwayne, Loren Brandt and Scott Rozelle. 2000. "Aging, Well-Being and Social Security in Rural North China," Population and Development Review, Vol 26: 89-116.

Bian, Fuqin, John R. Logan and Yanjie Bian. 1998. "Intergenerational Relations in Urban China: Proximity, Contact and Help to Parents," Demography, 35(1): 115-124.

Bound, John, Michael Schoenbaum, Todd R. Stinebrickner, and Timothy Waldmann. 1999. "The Dynamic Effects of Health on the Labor Force Transitions of Older Workers," Labour Economics, 6(2), pp. 17-27

Cai, Fang, John Giles and Xin Meng. 2006. "How Well Do Children Insure Parents Against Low Retirement Income? An Analysis Using Survey Data from Urban China," Journal of Public Economics (in press). 
Cai, Fang, Albert Park and Yaohui Zhao. 2006. "The Chinese Labor Market," chapter prepared for China's Economic Transition: Origins, Mechanisms and Consequences (Loren Brandt and Thomas Rawski, editors.), mimeograph, University of Michigan.

Cameron, Lisa and Deborah Cobb-Clark. 2001. "Old-Age Labour Supply in the Developing World," Applied Economics Letters v9, n10 (August 2002): 649-52.

Costa, Dora L. 1996. "Health and the Labor Force Participation of Older Men, 1900-1991," Journal of Economic History, 56(1): 62-89.

Davis-Friedman, Deborah. 1991. Long lives: Chinese elderly and the communist revolution. Stanford: Stanford University Press.

Fang, Yuan, Chuanbin Wang and Yuhua Song. 1992. "Support for the Elderly in China," in Family Support for the Elderly: The International Experience, Hal L. Kendig, Akiko Hashimoto, and Larry C. Copport (eds.). New York: Oxford University Press, pp. 250-259.

Hurd, Michael and Michael Boskin. 1984. "The Effect of Social Security on Retirement in the Early 1970s," Quarterly Journal of Economics, 99(4): 767-90.

Knodel, John and Napaporn Chayovan. 1997. "Family Support and Living Arrangements of Thai elderly," Asia-Pacific Population Journal 12(4): 51-68.

Lee, Yean-Ju and Zhenyu Xiao. 1998. "Children's Support for Elderly Parents in Urban and Rural China: Results from a National Survey," Journal of Cross-Cultural Gerontology 13: 39-62.

Liang, Zai and Zhongdong Ma. 2004. "China's Floating Population: New Evidence from the 2000 Census," Population and Development Review 30(3): 467-488.

Lin, Jiang. 1994. "Parity and Security: A Simulation Study of Old-Age Support in Rural China," Population and Development Review 20: 423-48.

Newhouse, Joseph and the Insurance Experiment Group. 1993. Free for All? Lessons from the RAND Health Insurance Experiment. Cambridge: Harvard University Press.

Pang, Lihua, Alan de Brauw, and Scott Rozelle. 2004. "Working Until You Drop: The Elderly of Rural China," China Journal 52, July 2004, 73-96.

Parsons, Donald O. 1980. "The Decline in Male Labor Force Participation," Journal of Political Economy, 88:1, pp. 117-34.

Selden, Mark. 1993. "Family Strategies and Structures in Rural North China," in Chinese Families in the Post-Mao Era, eds. Deborah Davis and Stevan Harrell. Berkeley: University of California Press, pp. 139-164. 
Strauss, John and Duncan Thomas. 1998. "Health, Nutrition and Economic Development," Journal of Economic Literature, 36(June 1998): 766-817.

Wooldridge, Jeffrey M. (2002). Econometric Analysis of Cross Section and Panel Data. MIT Press, Cambridge, 2002.

Wooldridge, Jeffrey (2006). Introductory Econometrics: A Modern Approach (3rd edition), Thomson South-Western, 2006.

World Bank. 1994. Averting the Old Age Crisis. New York: Oxford University Press for the World Bank.

Zimmer, Zachary and Sovan Kiry Kim. 2002. "Living Arrangements and Socio-Demographic Conditions of Older Adults in Cambodia," Population Council Working Paper, No. 157.

Zimmer, Zachary and Julia Kwong. 2003. "Family Size and Support of Older Adults in Urban and Rural China: Current Effects and Future Implications," Demography, Volume 40(1): 23-44. 
Figure 1. Living Arrangements of China's Rural Elderly in 2003 (RCRE), By Age

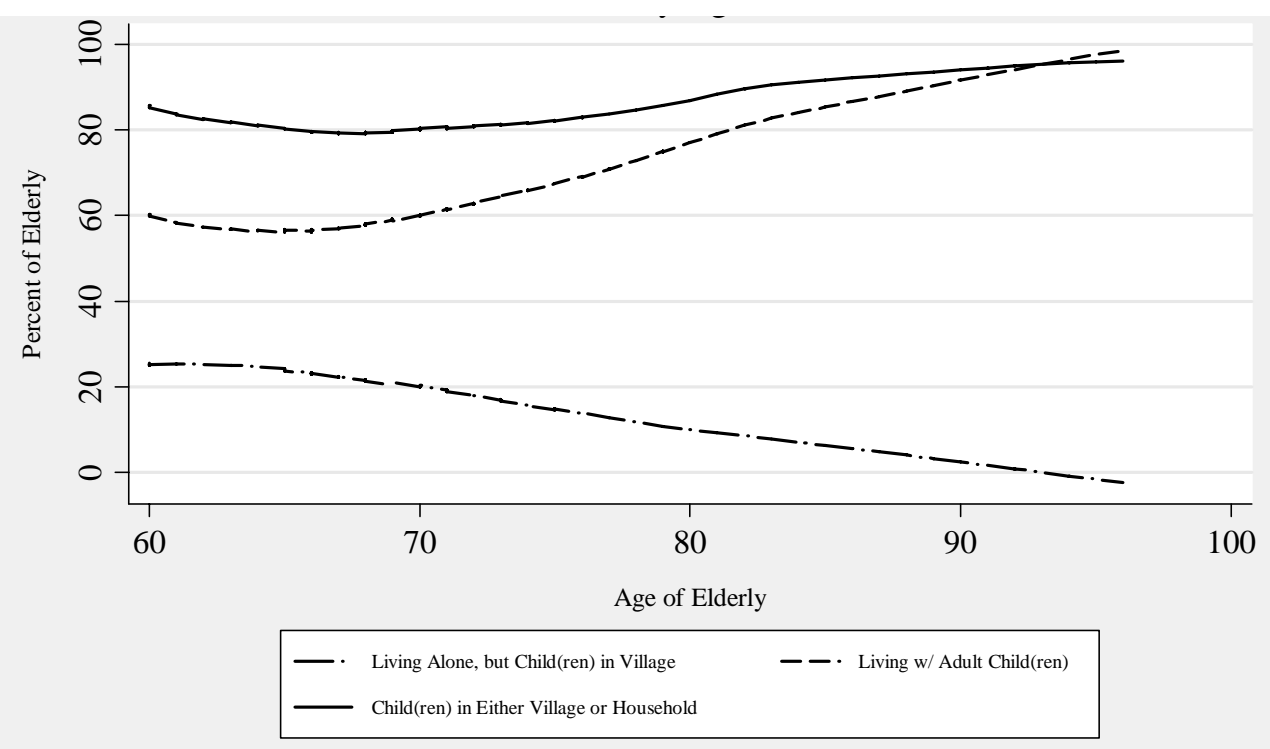

Notes: We show lowess plots (locally weighted non-parametric regression lines) for two groups of elderly: those living alone but with children in the village and those living with children. The solid line shows the lowess plot for elderly who have children either in the household or in the village. In principle, the two dashed lines sum to the solid line, and the omitted category are elderly living alone or with others who do not have children living in the village. Individual data come from the supplemental surveys carried out in collaboration with the authors in RCRE households of Anhui, Henan, Jiangsu and Shanxi provinces in 2004 (RCRE 2004 Supplemental). 
Figure 2. Age Cohort Share of 16-40 Year Olds Employed as Migrants by Timing of Parent Death

\section{Panel A: Men}

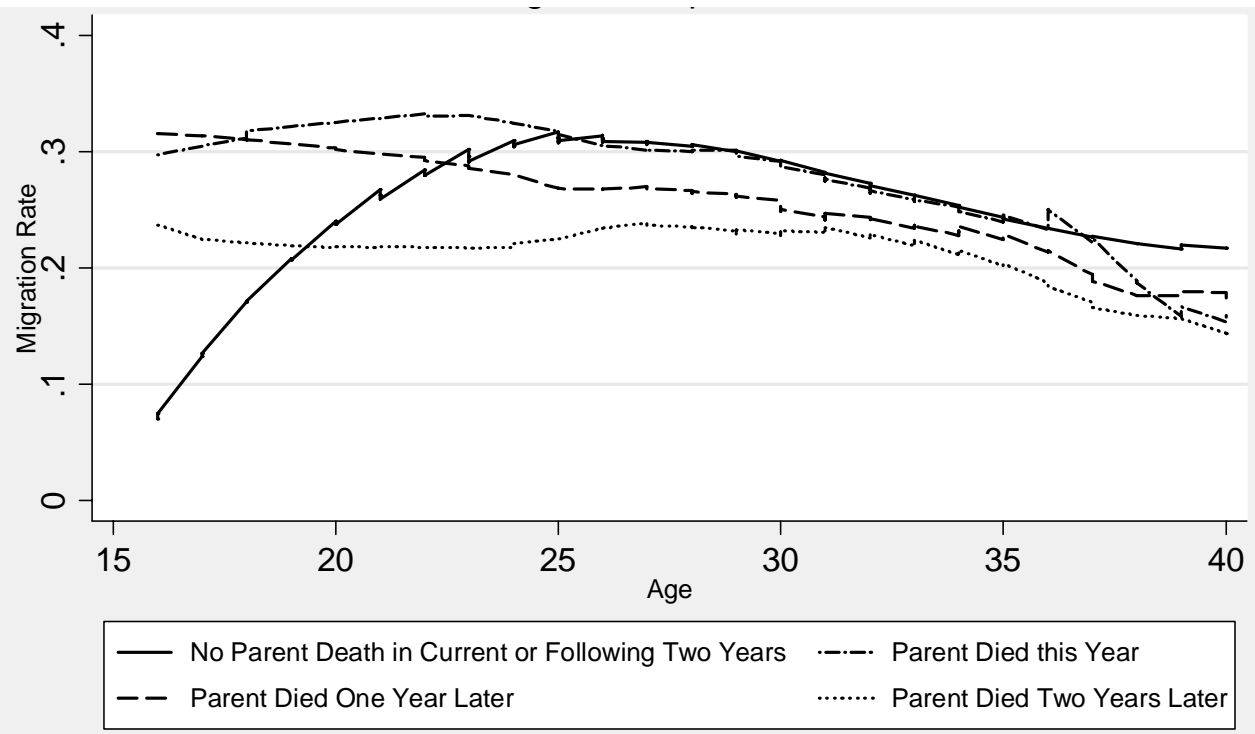

\section{Panel B: Women}

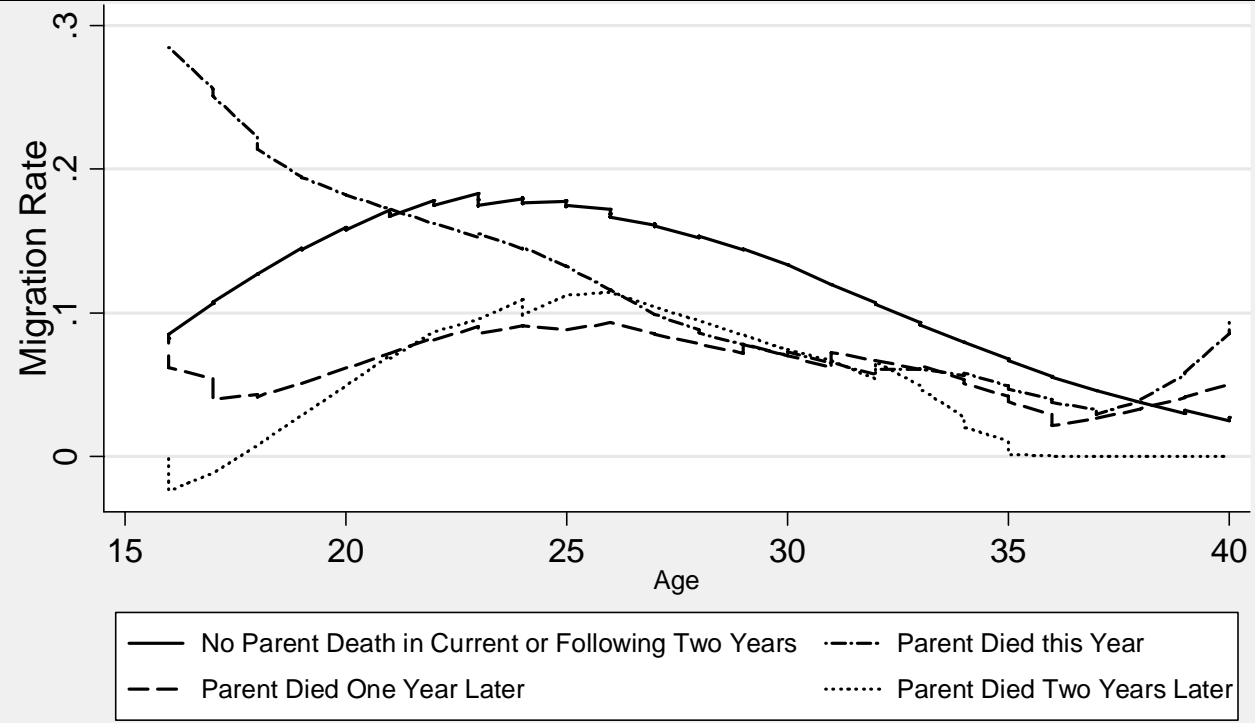

\footnotetext{
Notes: Migration rates are plotted using lowess smoothing. The figure shows migration rates of current and former male residents of RCRE households are broken into groups depending on the timing of parent death. Data are drawn from the RCRE 2004 Supplemental Survey of RCRE households in Anhui, Henan, Jiangsu and Shanxi province and reflect annual labor allocation decisions made between 1992 and 2004.
} 


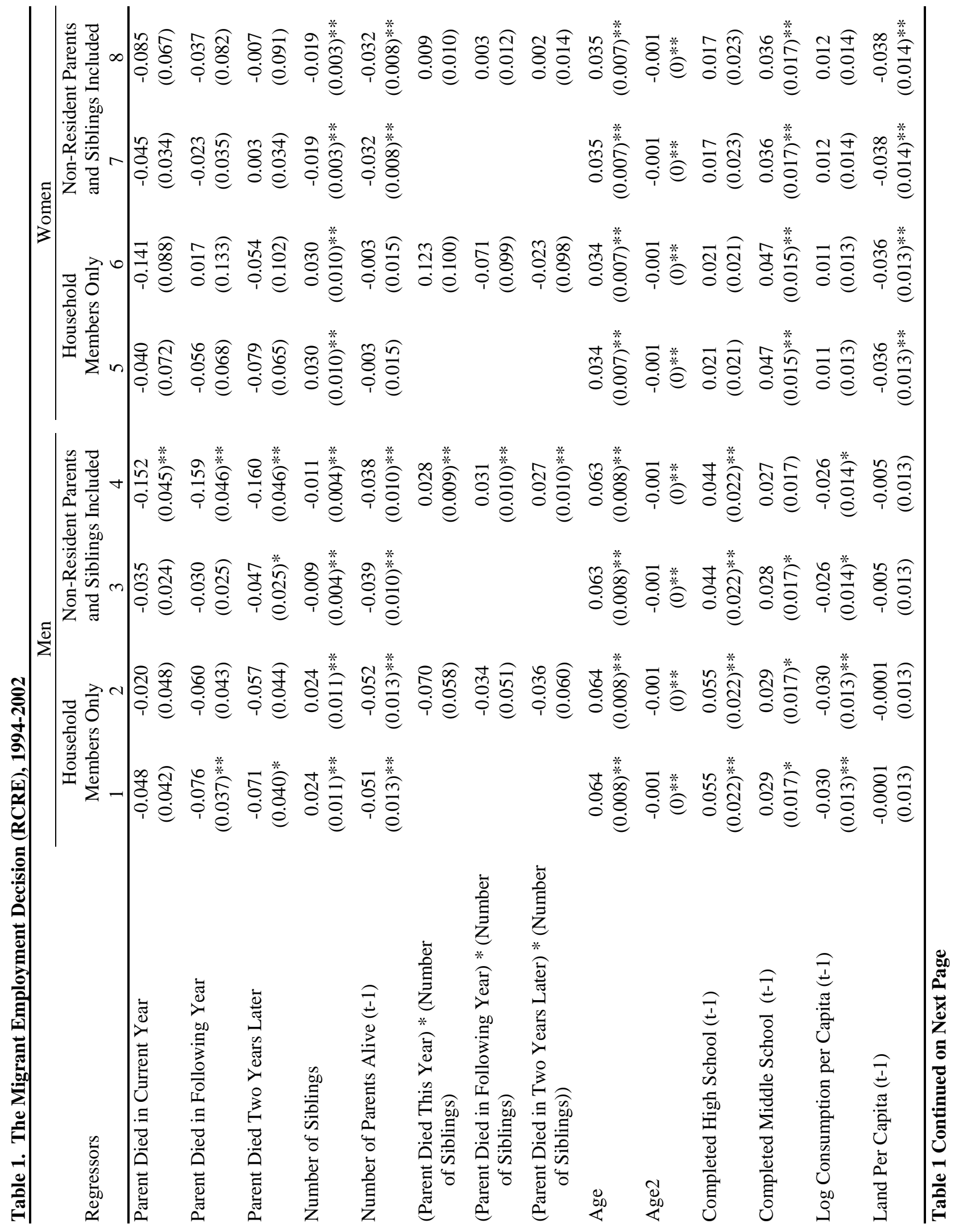




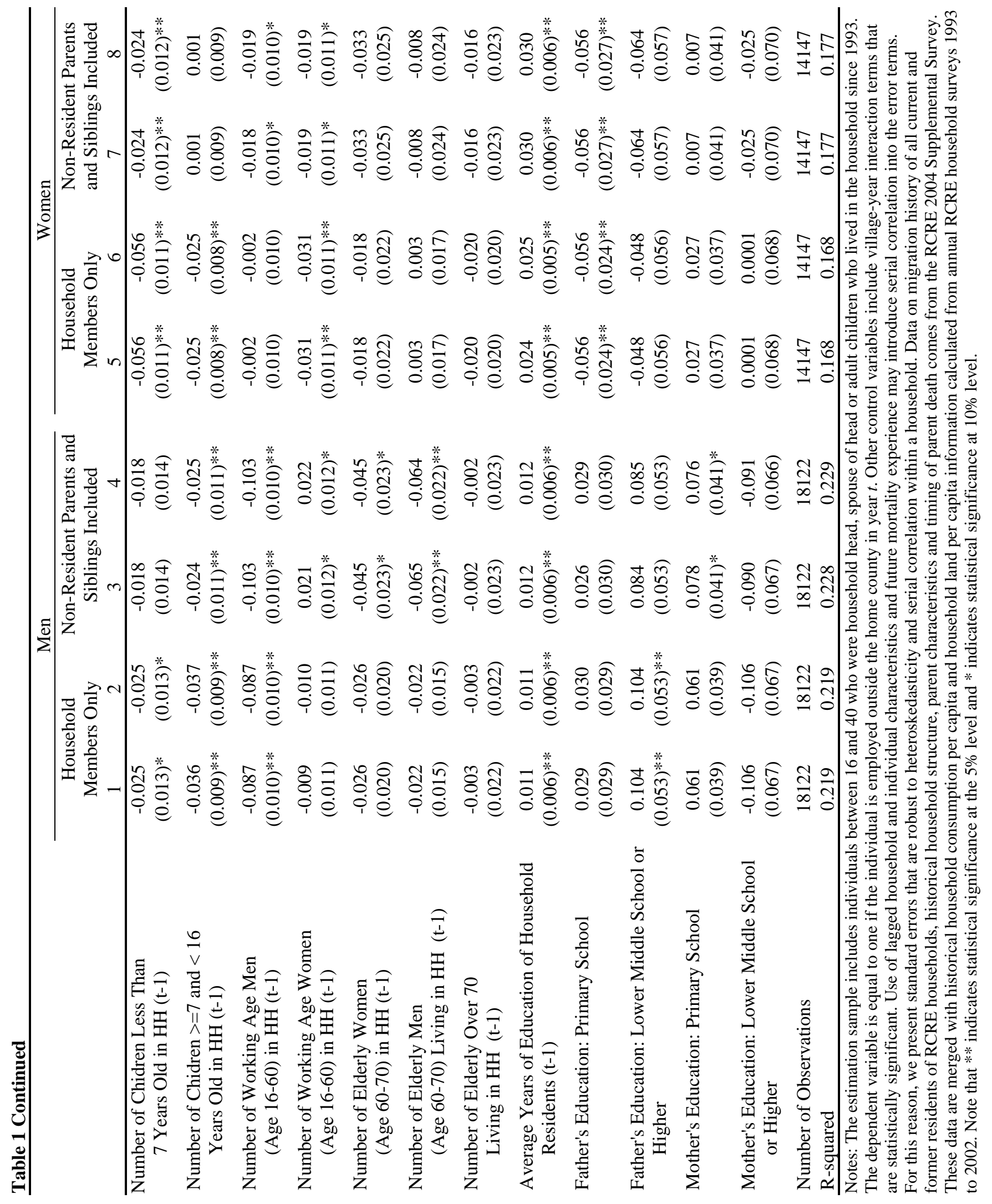


Table 2. First-Stage Regression for Change in Self-Reported Elderly Health

\begin{tabular}{|c|c|c|}
\hline & $\begin{array}{c}\text { Men } \\
\Delta \text { Lag Presence } \\
\text { of Elderly } \\
\text { w/H34 }\end{array}$ & $\begin{array}{c}\text { Women } \\
\Delta \text { Lag Presence } \\
\text { of Elderly } \\
\text { w/H34 }\end{array}$ \\
\hline$\Delta$ Lag Share of Elderly with High BMI & $\begin{array}{c}0.119 \\
(0.059)^{* *}\end{array}$ & $\begin{array}{c}0.046 \\
(0.061)\end{array}$ \\
\hline$\Delta$ Lag Share of Elderly with Low BMI & $\begin{array}{c}0.118 \\
(0.022)^{* *}\end{array}$ & $\begin{array}{c}0.085 \\
(0.022)^{* *}\end{array}$ \\
\hline $\begin{array}{l}\text { F-statistics for Test of Excluded Instruments } \\
\text { F-Probability }\end{array}$ & $\begin{array}{l}15.11 \\
0.000\end{array}$ & $\begin{array}{c}7.47 \\
0.0006\end{array}$ \\
\hline Observations & 2827 & 2552 \\
\hline
\end{tabular}

Note: Other variables in the first-stage regressions include: province*year fixed effects, change in lag own health status, change in lag own High BMI, change in lag own Low BMI, change of lag marital status, change of lag education level, change of lag household average years of schooling, change in lag number of children, change in lag number of working age men, change in lag number of working age women, change in lag number of elderly men and women from 60 to 70, and change in lag number of elderly over 70 . Standard errors are robust to heteroskedasticity and serial correlation within the household. Note that ** indicates statistical significance at the $5 \%$ level and * indicates statistical significance at $10 \%$ level. 
Table 3. Elder Parent Health and the Migration Decision, Conditional on Own Health

\begin{tabular}{|c|c|c|c|c|c|c|}
\hline & \multicolumn{3}{|c|}{ Men } & \multicolumn{3}{|c|}{ Women } \\
\hline & OLS & FD & FDIV & OLS & FD & FDIV \\
\hline $\begin{array}{l}\text { Elderly Member in Fair or Poor Health } \\
(\mathrm{H} 34) ?(\mathrm{t}-1)\end{array}$ & $\begin{array}{l}-0.017 \\
(0.014)\end{array}$ & $\begin{array}{l}-0.023 \\
(0.014)\end{array}$ & $\begin{array}{c}-0.260 \\
(0.108)^{* *}\end{array}$ & $\begin{array}{l}-0.010 \\
(0.014)\end{array}$ & $\begin{array}{c}-0.036 \\
(0.017)^{* *}\end{array}$ & $\begin{array}{l}-0.139 \\
(0.153)\end{array}$ \\
\hline Own Health Fair or Poor (H34) (t-1) & $\begin{array}{c}0.008 \\
(0.012)\end{array}$ & $\begin{array}{c}0.004 \\
(0.014)\end{array}$ & $\begin{array}{c}0.097 \\
(0.046)^{* *}\end{array}$ & $\begin{array}{c}0.014 \\
(0.011)\end{array}$ & $\begin{array}{l}-0.0008 \\
(0.014)\end{array}$ & $\begin{array}{c}0.037 \\
(0.057)\end{array}$ \\
\hline High BMI (t-1) & $\begin{array}{l}0.0001 \\
(0.011)\end{array}$ & $\begin{array}{l}-0.016 \\
(0.017)\end{array}$ & $\begin{array}{l}-0.020 \\
(0.018)\end{array}$ & $\begin{array}{c}0.004 \\
(0.009)\end{array}$ & $\begin{array}{l}-0.001 \\
(0.017)\end{array}$ & $\begin{array}{l}-0.003 \\
(0.018)\end{array}$ \\
\hline Low BMI (t-1) & $\begin{array}{l}-0.019 \\
(0.014)\end{array}$ & $\begin{array}{c}0.019 \\
(0.016)\end{array}$ & $\begin{array}{c}0.033 \\
(0.017)^{*}\end{array}$ & $\begin{array}{l}-0.020 \\
(0.016)\end{array}$ & $\begin{array}{c}0.003 \\
(0.017)\end{array}$ & $\begin{array}{c}-0.0004 \\
(0.018)\end{array}$ \\
\hline Marital Status (single $=1)(t-1)$ & $\begin{array}{c}0.019 \\
(0.011)^{*}\end{array}$ & $\begin{array}{c}-0.041 \\
(0.023)^{*}\end{array}$ & $\begin{array}{c}-0.037 \\
(0.025)\end{array}$ & $\begin{array}{c}0.052 \\
(0.009)^{* *}\end{array}$ & $\begin{array}{c}-0.118 \\
(0.055)^{* *}\end{array}$ & $\begin{array}{c}-0.113 \\
(0.057)^{* *}\end{array}$ \\
\hline Completed High School (t-1) & $\begin{array}{c}0.021 \\
(0.012)^{*}\end{array}$ & $\begin{array}{c}0.037 \\
(0.023)\end{array}$ & $\begin{array}{c}0.044 \\
(0.023)^{*}\end{array}$ & $\begin{array}{c}0.020 \\
(0.015)\end{array}$ & $\begin{array}{c}0.014 \\
(0.024)\end{array}$ & $\begin{array}{c}0.017 \\
(0.024)\end{array}$ \\
\hline Completed Middle School (t-1) & $\begin{array}{c}0.004 \\
(0.009)\end{array}$ & $\begin{array}{c}0.005 \\
(0.013)\end{array}$ & $\begin{array}{c}0.011 \\
(0.014)\end{array}$ & $\begin{array}{c}-0.012 \\
(0.009)\end{array}$ & $\begin{array}{c}-0.041 \\
(0.014)^{* *}\end{array}$ & $\begin{array}{c}-0.043 \\
(0.014)^{* *}\end{array}$ \\
\hline Average Years of Education (t-1) & $\begin{array}{c}0.003 \\
(0.002)\end{array}$ & $\begin{array}{c}-0.007 \\
(0.004)^{*}\end{array}$ & $\begin{array}{c}-0.012 \\
(0.005)^{* *}\end{array}$ & $\begin{array}{l}-0.0001 \\
(0.002)\end{array}$ & $\begin{array}{c}-0.001 \\
(0.004)\end{array}$ & $\begin{array}{c}-0.003 \\
(0.004)\end{array}$ \\
\hline Ln(Household Income Per Capita) (t-1) & $\begin{array}{c}-0.010 \\
(0.006)^{*}\end{array}$ & $\begin{array}{c}0.019 \\
(0.012)\end{array}$ & $\begin{array}{c}0.033 \\
(0.014)^{* *}\end{array}$ & $\begin{array}{c}-0.010 \\
(0.006)\end{array}$ & $\begin{array}{c}0.014 \\
(0.014)\end{array}$ & $\begin{array}{c}0.018 \\
(0.016)\end{array}$ \\
\hline Land Per Capita (t-1) & $\begin{array}{c}-0.009 \\
(0.005)^{*}\end{array}$ & $\begin{array}{c}-0.016 \\
(0.011)\end{array}$ & $\begin{array}{c}-0.010 \\
(0.012)\end{array}$ & $\begin{array}{c}-0.011 \\
(0.005)^{* *}\end{array}$ & $\begin{array}{c}-0.033 \\
(0.013)^{* *}\end{array}$ & $\begin{array}{c}-0.032 \\
(0.013)^{* *}\end{array}$ \\
\hline Number of Chidren (Age 0-6) (t-1) & $\begin{array}{c}0.023 \\
(0.006)^{* *}\end{array}$ & $\begin{array}{c}0.013 \\
(0.013)\end{array}$ & $\begin{array}{c}0.017 \\
(0.014)\end{array}$ & $\begin{array}{c}0.023 \\
(0.008)^{* *}\end{array}$ & $\begin{array}{c}0.010 \\
(0.020)\end{array}$ & $\begin{array}{c}0.006 \\
(0.020)\end{array}$ \\
\hline Number of Children (Age 7-15) (t-1) & $\begin{array}{c}0.012 \\
(0.006)^{* *}\end{array}$ & $\begin{array}{c}0.003 \\
(0.014)\end{array}$ & $\begin{array}{c}0.006 \\
(0.015)\end{array}$ & $\begin{array}{c}0.024 \\
(0.006)^{* *}\end{array}$ & $\begin{array}{c}-0.003 \\
(0.014)\end{array}$ & $\begin{array}{c}0.001 \\
(0.015)\end{array}$ \\
\hline $\begin{array}{l}\text { Number of Working Age Men } \\
\text { (Age 16-60) (t-1) }\end{array}$ & $\begin{array}{c}0.041 \\
(0.018)^{* *}\end{array}$ & $\begin{array}{c}0.035 \\
(0.030)\end{array}$ & $\begin{array}{c}0.071 \\
(0.036)^{* *}\end{array}$ & $\begin{array}{c}0.047 \\
(0.021)^{* *}\end{array}$ & $\begin{array}{c}0.127 \\
(0.036)^{* *}\end{array}$ & $\begin{array}{c}0.136 \\
(0.038)^{* *}\end{array}$ \\
\hline $\begin{array}{l}\text { Number of Working Age Women } \\
(\text { Age } 16-60)(t-1)\end{array}$ & $\begin{array}{c}0.034 \\
(0.018)^{*}\end{array}$ & $\begin{array}{c}0.042 \\
(0.029)\end{array}$ & $\begin{array}{c}0.061 \\
(0.033)^{*}\end{array}$ & $\begin{array}{c}0.016 \\
(0.019)\end{array}$ & $\begin{array}{c}0.024 \\
(0.031)\end{array}$ & $\begin{array}{c}0.043 \\
(0.041)\end{array}$ \\
\hline $\begin{array}{l}\text { Number of Elderly Women (Age 60-70) } \\
(\mathrm{t}-1)\end{array}$ & $\begin{array}{c}0.017 \\
(0.009)^{*}\end{array}$ & $\begin{array}{c}0.018 \\
(0.012)\end{array}$ & $\begin{array}{c}0.034 \\
(0.015)^{* *}\end{array}$ & $\begin{array}{l}-0.007 \\
(0.008)\end{array}$ & $\begin{array}{l}-0.012 \\
(0.013)\end{array}$ & $\begin{array}{l}-0.005 \\
(0.018)\end{array}$ \\
\hline $\begin{array}{l}\text { Number of Elderly Men (Age 60-70) } \\
(\mathrm{t}-1)\end{array}$ & $\begin{array}{l}-0.001 \\
(0.002)\end{array}$ & $\begin{array}{c}0.002 \\
(0.003)\end{array}$ & $\begin{array}{c}0.003 \\
(0.003)\end{array}$ & $\begin{array}{c}0.001 \\
(0.002)\end{array}$ & $\begin{array}{c}0.003 \\
(0.003)\end{array}$ & $\begin{array}{c}0.003 \\
(0.003)\end{array}$ \\
\hline Number of Elderly Over Age 70 (t-1) & $\begin{array}{l}-0.005 \\
(0.005)\end{array}$ & $\begin{array}{l}-0.002 \\
(0.012)\end{array}$ & $\begin{array}{l}-0.004 \\
(0.013)\end{array}$ & $\begin{array}{l}-0.004 \\
(0.006)\end{array}$ & $\begin{array}{c}0.006 \\
(0.012)\end{array}$ & $\begin{array}{c}0.006 \\
(0.012)\end{array}$ \\
\hline $\begin{array}{l}\text { F-Statistics (Old Member SRHS) } \\
\text { F-Probability }\end{array}$ & & & $\begin{array}{l}15.11 \\
0.000\end{array}$ & & & $\begin{array}{c}7.47 \\
0.0006\end{array}$ \\
\hline $\begin{array}{l}\text { Over-ID Test: Hansen J-Statistic } \\
\text { Chi-Probability }\end{array}$ & & & $\begin{array}{c}2.666 \\
0.1025\end{array}$ & & & $\begin{array}{c}0.923 \\
0.3368\end{array}$ \\
\hline Number of obs & 4540 & 2827 & 2827 & 4227 & 2552 & 2552 \\
\hline
\end{tabular}

Notes: The dependent variable is one if an individual in the household in period t-1 lives in another county in period t, the dependent variable equals negative 1 if an individual not residing in the household in $\mathrm{t}-1$ returns in period t, otherwise the dependent variable is zero. FDIV models are estimated using IV-GMM estimation (Wooldridge, 2002, pg. 193) which is the most efficient estimation approach robust to heteroskedasticity and serial correlation within survey clusters. All models include province-year fixed effects. Note that ** indicates statistical significance at the $5 \%$ level and * indicates statistical significance at $10 \%$ level. 


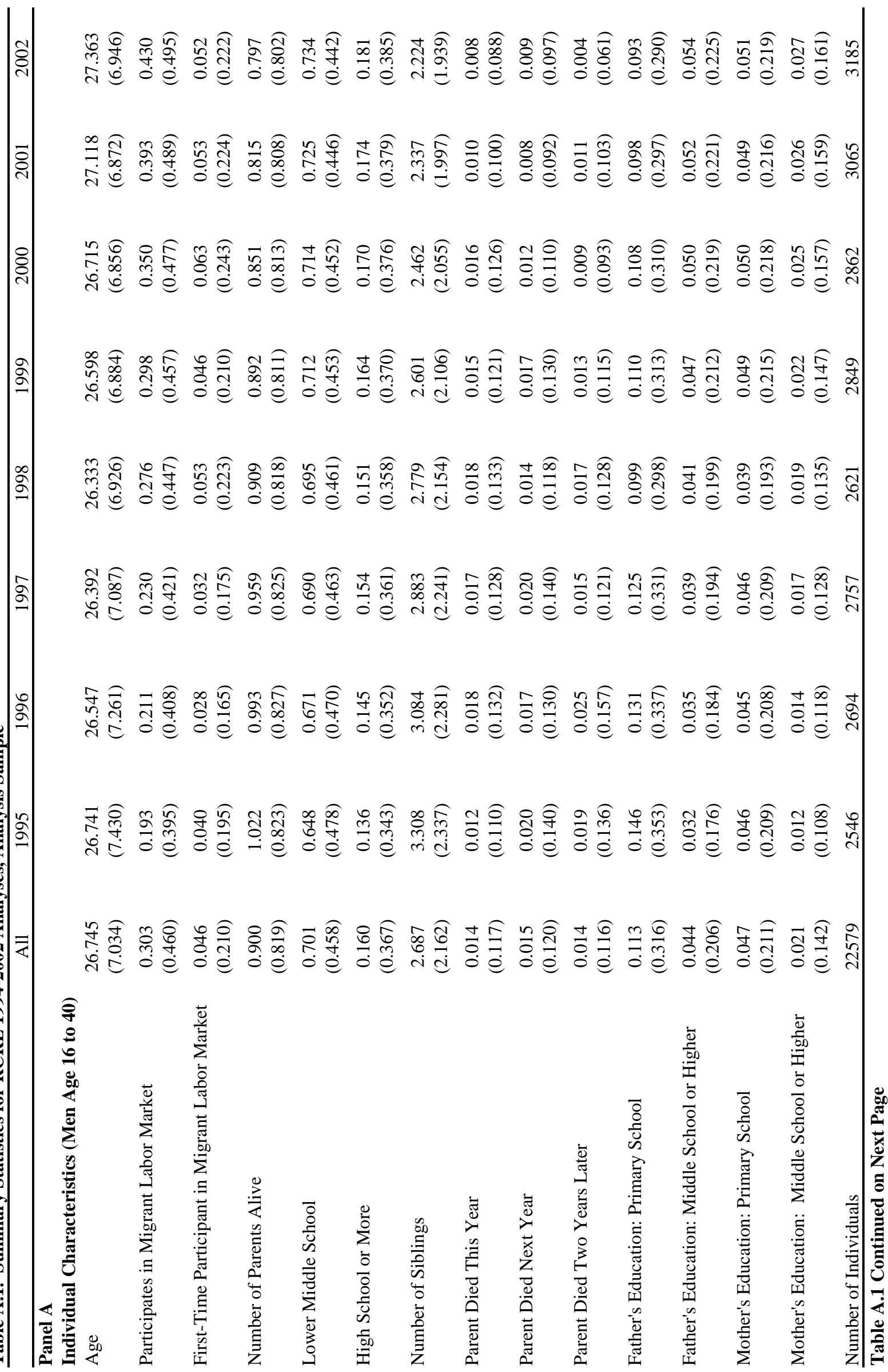




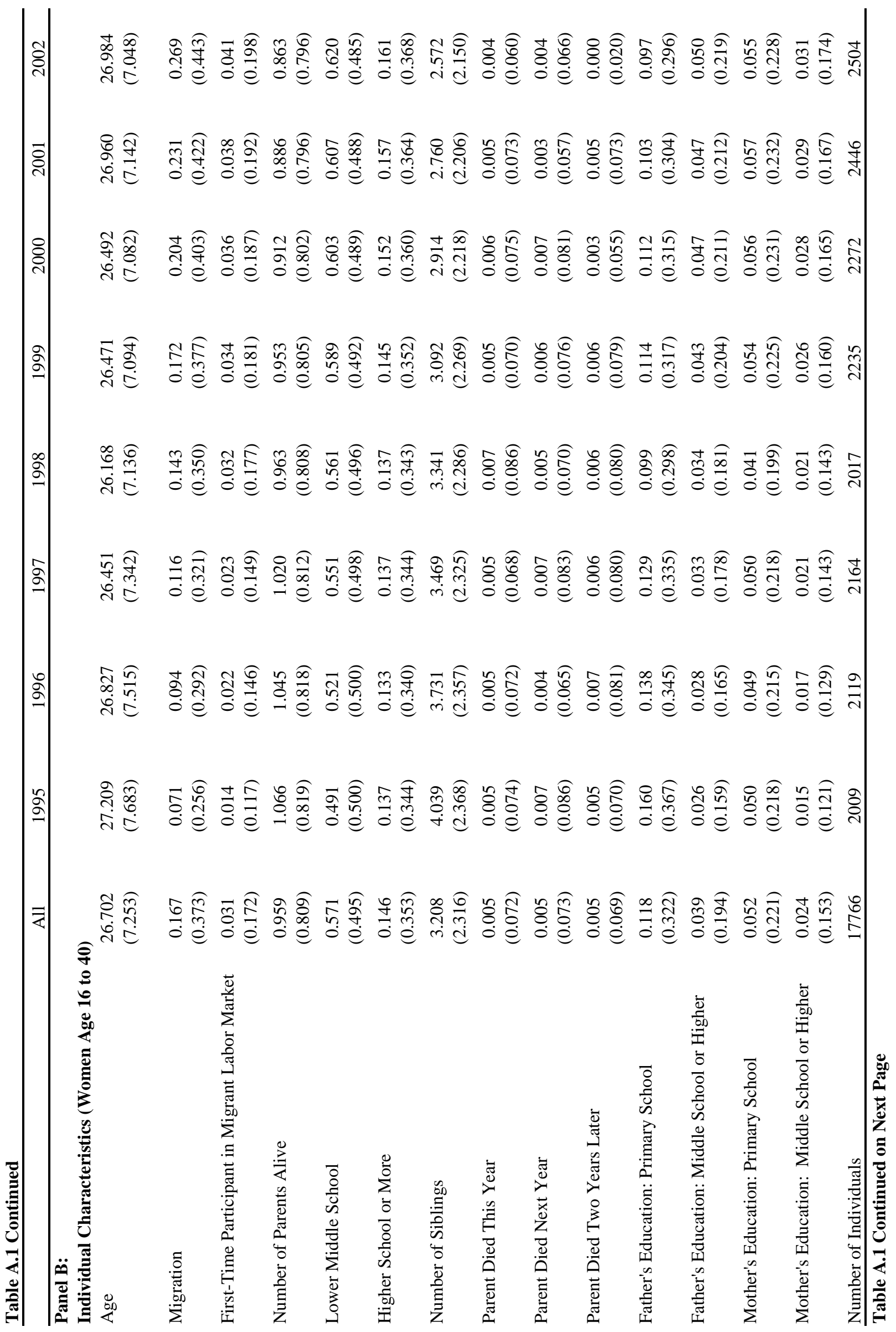




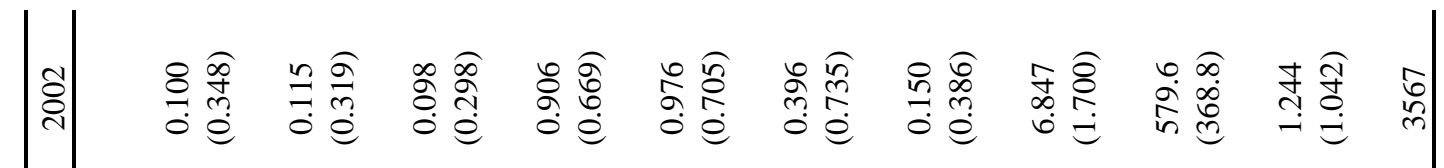

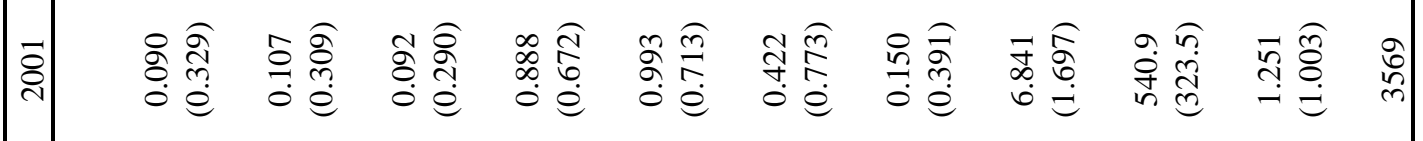

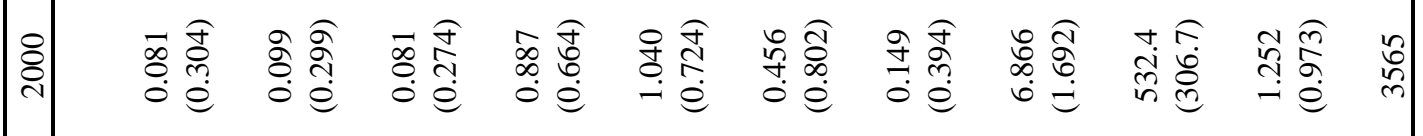

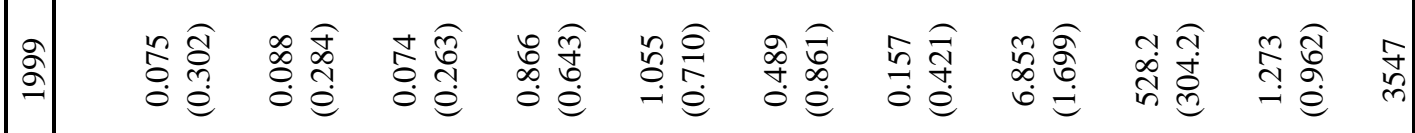

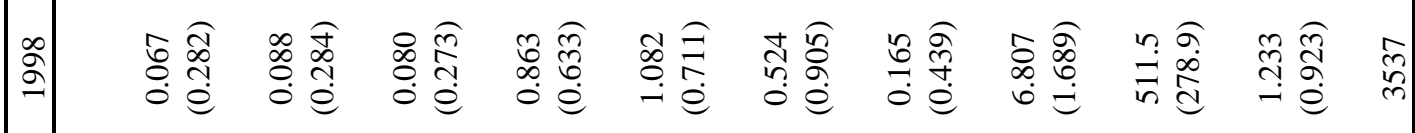

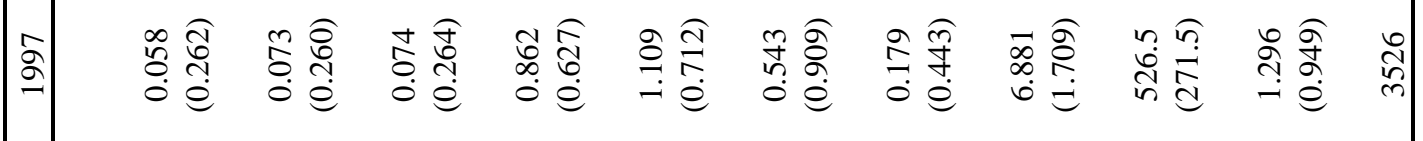

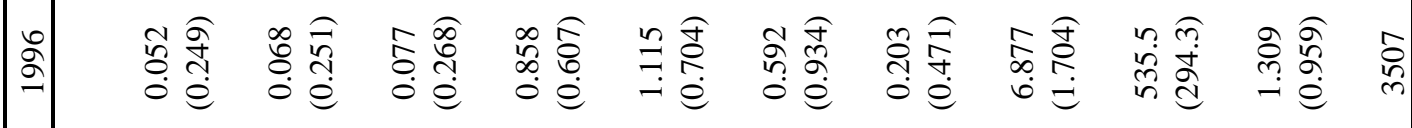

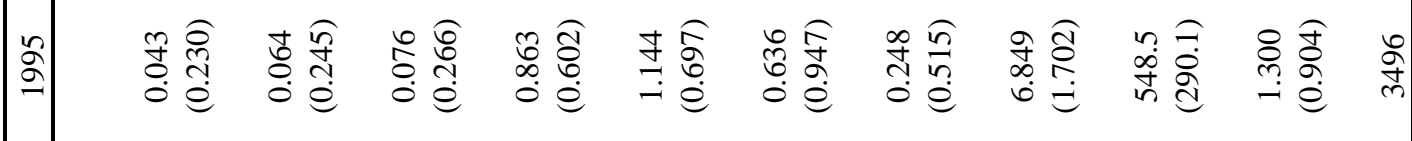

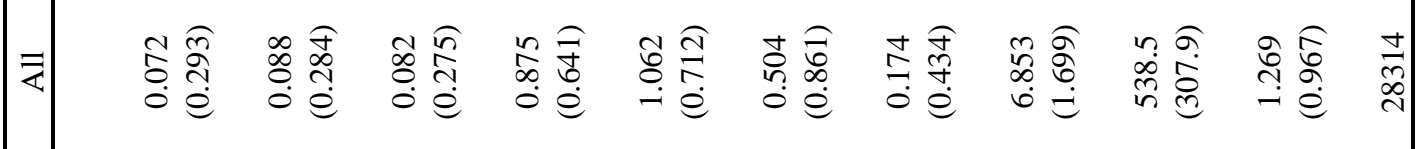

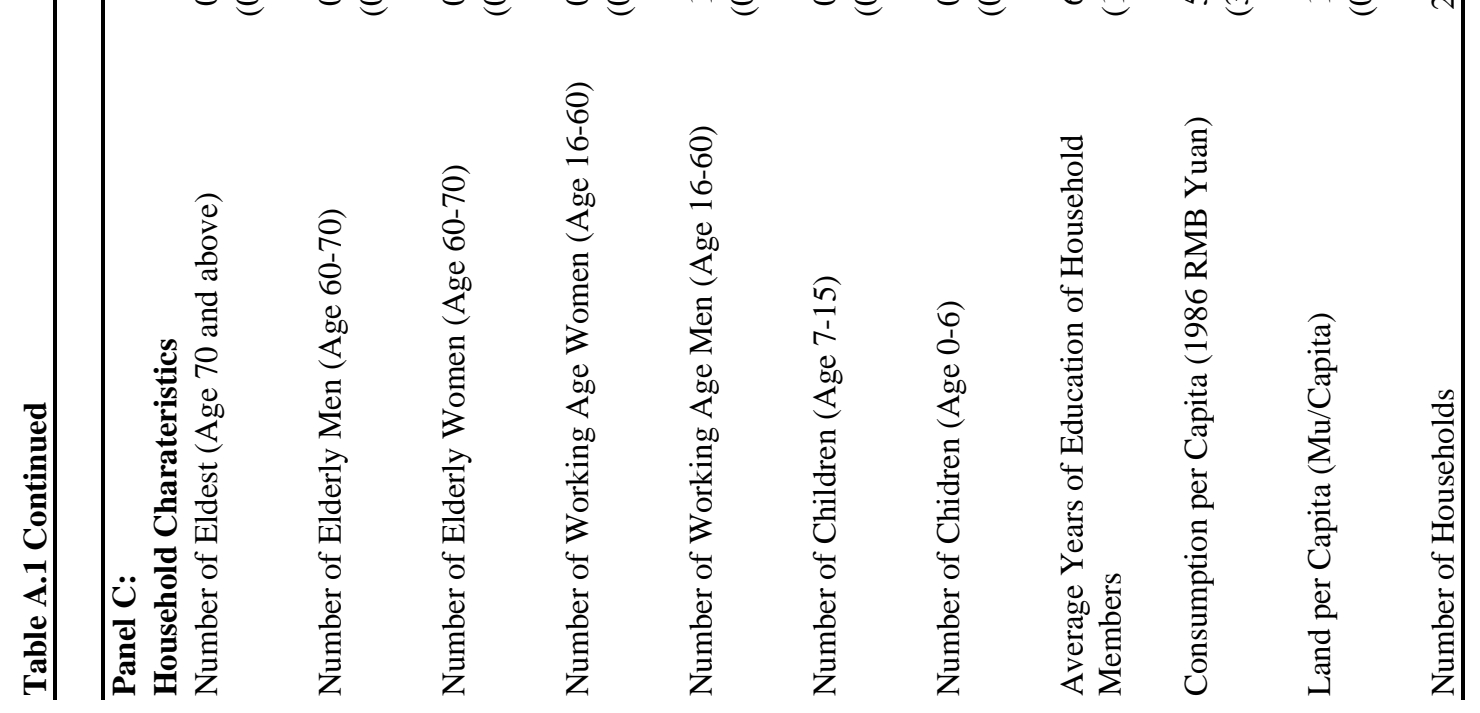


Table A.2. Summary Statistics for CHNS Analysis Sample

\begin{tabular}{|c|c|c|c|c|c|}
\hline & All & 1991 & 1993 & 1997 & 2000 \\
\hline \multicolumn{6}{|l|}{$\begin{array}{l}\text { Panel A: Individual Charateristics } \\
\text { (Men 16-40 Years of Age) }\end{array}$} \\
\hline Age & $\begin{array}{l}26.99 \\
(7.17)\end{array}$ & $\begin{array}{l}27.16 \\
(7.61)\end{array}$ & $\begin{array}{l}26.72 \\
(7.30)\end{array}$ & $\begin{array}{l}26.94 \\
(6.81)\end{array}$ & $\begin{array}{l}27.18 \\
(6.95)\end{array}$ \\
\hline $\begin{array}{l}\text { Migrated from Household Between t-1 } \\
\text { and t }\end{array}$ & $\begin{array}{c}0.07 \\
(0.25)\end{array}$ & & $\begin{array}{c}0.06 \\
(0.25)\end{array}$ & $\begin{array}{c}0.10 \\
(0.30)\end{array}$ & $\begin{array}{c}0.11 \\
(0.31)\end{array}$ \\
\hline Middle School Graduate & $\begin{array}{c}0.66 \\
(0.47)\end{array}$ & $\begin{array}{c}0.64 \\
(0.48)\end{array}$ & $\begin{array}{c}0.62 \\
(0.48)\end{array}$ & $\begin{array}{c}0.67 \\
(0.47)\end{array}$ & $\begin{array}{c}0.71 \\
(0.45)\end{array}$ \\
\hline High School Graudate or Higher & $\begin{array}{c}0.18 \\
(0.39)\end{array}$ & $\begin{array}{c}0.16 \\
(0.37)\end{array}$ & $\begin{array}{c}0.16 \\
(0.36)\end{array}$ & $\begin{array}{c}0.21 \\
(0.40)\end{array}$ & $\begin{array}{c}0.22 \\
(0.41)\end{array}$ \\
\hline Single & $\begin{array}{c}0.52 \\
(0.50)\end{array}$ & $\begin{array}{c}0.42 \\
(0.49)\end{array}$ & $\begin{array}{c}0.51 \\
(0.50)\end{array}$ & $\begin{array}{c}0.56 \\
(0.50)\end{array}$ & $\begin{array}{c}0.58 \\
(0.49)\end{array}$ \\
\hline Fair or Poor Health (H34=1) & $\begin{array}{c}0.01 \\
(0.11)\end{array}$ & $\begin{array}{c}0.01 \\
(0.12)\end{array}$ & $\begin{array}{c}0.01 \\
(0.11)\end{array}$ & $\begin{array}{c}0.01 \\
(0.09)\end{array}$ & $\begin{array}{c}0.01 \\
(0.11)\end{array}$ \\
\hline High BMI & $\begin{array}{l}0.15 \\
(0.35)\end{array}$ & $\begin{array}{c}0.15 \\
(0.36)\end{array}$ & $\begin{array}{c}0.16 \\
(0.36)\end{array}$ & $\begin{array}{c}0.12 \\
(0.32)\end{array}$ & $\begin{array}{c}0.16 \\
(0.36)\end{array}$ \\
\hline Low BMI & $\begin{array}{c}0.04 \\
(0.20)\end{array}$ & $\begin{array}{c}0.02 \\
(0.15)\end{array}$ & $\begin{array}{c}0.02 \\
(0.15)\end{array}$ & $\begin{array}{c}0.05 \\
(0.22)\end{array}$ & $\begin{array}{c}0.08 \\
(0.27)\end{array}$ \\
\hline Number of Individuals & 6631 & 1577 & 1732 & 1757 & 1565 \\
\hline \multicolumn{6}{|l|}{$\begin{array}{l}\text { Panel B: Individual Charateristics } \\
\text { (Women 16-40 Years of Age) }\end{array}$} \\
\hline Age & $\begin{array}{l}27.01 \\
(7.10)\end{array}$ & $\begin{array}{l}27.15 \\
(7.51)\end{array}$ & $\begin{array}{l}26.75 \\
(7.18)\end{array}$ & $\begin{array}{l}26.96 \\
(6.73)\end{array}$ & $\begin{array}{l}27.22 \\
(6.95)\end{array}$ \\
\hline $\begin{array}{l}\text { Migrated from Household Between t-1 } \\
\text { and t }\end{array}$ & $\begin{array}{c}0.06 \\
(0.23)\end{array}$ & & $\begin{array}{c}0.05 \\
(0.22)\end{array}$ & $\begin{array}{c}0.07 \\
(0.26)\end{array}$ & $\begin{array}{c}0.10 \\
(0.30)\end{array}$ \\
\hline Middle School Graduate & $\begin{array}{c}0.49 \\
(0.50)\end{array}$ & $\begin{array}{c}0.45 \\
(0.50)\end{array}$ & $\begin{array}{c}0.45 \\
(0.50)\end{array}$ & $\begin{array}{c}0.52 \\
(0.50)\end{array}$ & $\begin{array}{c}0.56 \\
(0.50)\end{array}$ \\
\hline High School Graudate or Higher & $\begin{array}{c}0.12 \\
(0.33)\end{array}$ & $\begin{array}{c}0.10 \\
(0.30)\end{array}$ & $\begin{array}{c}0.10 \\
(0.30)\end{array}$ & $\begin{array}{c}0.14 \\
(0.35)\end{array}$ & $\begin{array}{c}0.16 \\
(0.37)\end{array}$ \\
\hline Single & $\begin{array}{c}0.48 \\
(0.50)\end{array}$ & $\begin{array}{c}0.38 \\
(0.48)\end{array}$ & $\begin{array}{c}0.48 \\
(0.50)\end{array}$ & $\begin{array}{c}0.53 \\
(0.50)\end{array}$ & $\begin{array}{c}0.54 \\
(0.50)\end{array}$ \\
\hline Fair or Poor Health (H34=1) & $\begin{array}{c}0.02 \\
(0.13)\end{array}$ & $\begin{array}{c}0.02 \\
(0.13)\end{array}$ & $\begin{array}{c}0.02 \\
(0.13)\end{array}$ & $\begin{array}{c}0.02 \\
(0.12)\end{array}$ & $\begin{array}{c}0.03 \\
(0.16)\end{array}$ \\
\hline High BMI & $\begin{array}{c}0.19 \\
(0.40)\end{array}$ & $\begin{array}{c}0.23 \\
(0.42)\end{array}$ & $\begin{array}{c}0.21 \\
(0.41)\end{array}$ & $\begin{array}{c}0.14 \\
(0.35)\end{array}$ & $\begin{array}{c}0.16 \\
(0.37)\end{array}$ \\
\hline Low BMI & $\begin{array}{c}0.04 \\
(0.19)\end{array}$ & $\begin{array}{c}0.02 \\
(0.15)\end{array}$ & $\begin{array}{c}0.03 \\
(0.17)\end{array}$ & $\begin{array}{c}0.03 \\
(0.18)\end{array}$ & $\begin{array}{c}0.08 \\
(0.27)\end{array}$ \\
\hline Number of Individuals & 6142 & 1526 & 1668 & 1697 & 1251 \\
\hline
\end{tabular}

Table A.2 Continued on Following Page 
Table A.2 Continued

\begin{tabular}{lccccc}
\hline & All & 1991 & 1993 & 1997 & 2000 \\
\hline Panel C: Household Demographic Structure & & & & & \\
Number of Eldest (Age 70 and above) & 0.20 & 0.11 & 0.15 & 0.28 & 0.26 \\
& $(0.56)$ & $(0.34)$ & $(0.41)$ & $(0.74)$ & $(0.65)$ \\
Number of Elderly Men (Age 60-70) & 0.12 & 0.09 & 0.11 & 0.15 & 0.14 \\
& $(0.33)$ & $(0.29)$ & $(0.31)$ & $(0.36)$ & $(0.35)$ \\
Number of Elderly Women (Age 60-70) & 0.12 & 0.08 & 0.12 & 0.15 & 0.15 \\
& $(0.33)$ & $(0.28)$ & $(0.32)$ & $(0.36)$ & $(0.35)$ \\
Number of Working Age Women (Age & 1.54 & 1.39 & 1.56 & 1.63 & 1.59 \\
16-60) & $(0.89)$ & $(0.77)$ & $(0.92)$ & $(0.96)$ & $(0.91)$ \\
Number of Working Age Men (Age 16- & 1.55 & 1.41 & 1.54 & 1.61 & 1.64 \\
60) & $(0.81)$ & $(0.75)$ & $(0.84)$ & $(0.85)$ & $(0.80)$ \\
Number of Children (Age 7-15) & 0.86 & 0.92 & 0.94 & 0.84 & 0.71 \\
& $(0.94)$ & $(0.93)$ & $(0.97)$ & $(0.97)$ & $(0.86)$ \\
Number of Chidren (Age 0-6) & 0.37 & 0.64 & 0.43 & 0.20 & 0.20 \\
Household Members Average Years of & $(0.65)$ & $(0.81)$ & $(0.67)$ & $(0.47)$ & $(0.47)$ \\
Schooling & 5.63 & 5.15 & 5.11 & 5.96 & 6.48 \\
Income Per Capita (1986 RMB Yuan) & $(2.20)$ & $(2.09)$ & $(2.01)$ & $(2.14)$ & $(2.28)$ \\
& 663.83 & 414.81 & 576.98 & 717.56 & 1005.49 \\
Land Per Capita (Mu/Capita) & $(1678.89)$ & $(626.83)$ & $(1408.94)$ & $(1445.49)$ & $(2715.77)$ \\
& 0.83 & 0.86 & 0.88 & 0.78 & 0.78 \\
Panel D: Health Status of Household Members & $(0.99)$ & $(0.66)$ & $(1.17)$ & $(0.97)$ & $(1.11)$ \\
Households With Elderly an Member in & 0.13 & 0.11 & 0.10 & 0.14 & 0.18 \\
Fair or Poor Health (H34=1) & $(0.34)$ & $(0.31)$ & $(0.30)$ & $(0.35)$ & $(0.38)$ \\
Share of Elderly with High BMI & 0.04 & 0.03 & 0.03 & 0.06 & 0.05 \\
Share of Elderly with Low BMI & $(0.19)$ & $(0.16)$ & $(0.15)$ & $(0.25)$ & $(0.19)$ \\
Standardized Difference Between Min & 0.04 & 0.02 & 0.01 & 0.09 & 0.04 \\
and Max BMI in Household & $(0.26)$ & $(0.15)$ & $(0.11)$ & $(0.44)$ & $(0.17)$ \\
Number of Households & 0.43 & 0.40 & 0.41 & 0.43 & 0.46 \\
& $(0.23)$ & $(0.23)$ & $(0.21)$ & $(0.25)$ & $(0.21)$ \\
& 6459 & 1636 & 1682 & 1665 & 1476 \\
\hline
\end{tabular}


Unpublished Supplementary Appendix Materials for Elder Parent Health and the Migration Decision of Adult Children: Evidence from Rural China

John Giles and Ren Mu

April 25, 2006 


\section{EXPANDED BACKGROUND DISCUSSION}

\section{China's Demographic Transition and the Welfare of the Elderly}

Successful efforts to limit fertility have contributed to the dramatic aging of China's population. Birth rates first started to fall with the "later, longer, fewer" campaign of the 1970s and then this decline became more dramatic with full implementation of the "one-child policy" after 1979. The results of fertility control policy are evident in Figure S.1. By 2000, China's population pyramid was nearly diamond shaped, and in the next few decades it may well resemble an inverted pyramid.

Decline in family size may ultimately lead to a breakdown of the traditional support system, but conclusions from research spanning literatures in demography and economics are not in agreement on this point. Zimmer and Kwong (2003) show that more children increase the likelihood that the elderly will receive support, but present simulation results that suggest that declines in fertility alone will not lead to collapse of family-based support for the elderly. ${ }^{1}$ Other research has suggested that financial transfers to parents respond to low income and low health status in urban areas (Cai, Giles and Meng, 2006), but that in rural areas inter-household transfers are often not observed because they take the form of labor input into family farming (Lee and Xiao, 1998). ${ }^{2}$

In addition to social pressure, which may be brought to bear to enforce provision of support to the elderly, the primacy of traditional support mechanisms was codified into China's laws from early in the history of the People's Republic. The Marriage Law of 1950 states that children should support elderly parents, and the Constitution of 1954 emphasized that children have a "duty" to support parents (see World Bank, 1994; and Fang, Wang and Song, 1992). The Marriage Law of 1980 further emphasized this responsibility, and provides elderly parents with the right to sue children for support if they fail to provide assistance. ${ }^{3}$

\footnotetext{
${ }^{1}$ This result is consistent with simulations based on data from the 1987 Aged Population Survey which suggested that in spite of declining fertility, the rural population will be able to support elderly parents (Lin 1994).

${ }^{2}$ Using other methods, Cameron and Cobb-Clark (2002) do not find evidence that transfers to parents respond to low parent income in Indonesia.

${ }^{3}$ The Chinese Marriage Law, Section 3, Article 21 states that "Parents shall be under the obligation for the upbringing and educating of their children, and children are also under obligation to support their
} 
The difficulty of enforcing family laws in China notwithstanding, these amendments to the marriage law and continued emphasis on using the law to maintain traditional family-based support reflects official determination to maintain the traditional system in the face of increasing pressures from the demographic transition and opportunities that have arisen with market reforms.

In terms of understanding the well-being of the elderly, most research has relied on indirect evidence suggested either by patterns of living arrangements or by labor supply and retirement decisions. Observed changes in living arrangements have been cited most frequently as reasons for concern for the well-being of the elderly. ${ }^{4}$ The decline in co-residence with adult children is even evident over the four rounds, from 1991 to 2000, of the China Health and Nutrition Survey (CHNS). Figure S.2 shows that in the CHNS, nearly 70 percent of adults in rural areas lived with an adult child in 1991, but by 2000 this share had fallen to around 60 percent. Similarly, the corresponding drop in urban areas was from roughly 60 percent in 1991 to just under 50 percent in 2000.

The change in living arrangements over both the long (from the 1930s to the 1990s as noted in Benjamin et al (2000)) and the short-run (from 1991 to 2000) does not necessarily reflect a drop in the provision of care to the elderly. In-kind transfers, such as supply of labor on extended family plots and provision of care, are difficult to pick up in surveys, yet such transfers often occur both within and across households. In a study of elder support in Shanghai and Tianjin, for example, Bian et al (1998) found that non-resident sons and daughters frequently live near elderly parents and provide regular non-financial assistance to them. Changes in living arrangements reflect the increasing wealth of families. With increasing resources, co-residence may not be necessary to care for the elderly. Within villages

parents.... Where any child fails to perform his or her obligations, parents who are unable to work or who are living a difficult life shall be entitled to ask their child to pay aliments (funds necessary to support basic housing and nourishment)." (Author's translation from 'Decision on Amending the Marriage Law of the People's Republic of China made at the 21st meeting of the Standing Committee of the Ninth National People's Congress', April 28, 2001).

${ }^{4}$ Selden (1993) concludes that a transition to the nuclear family imposes a heavy price on the rural elderly. Benjamin, Brandt and Rozelle (2000) note that in Northern China over 85 percent of elderly lived in extended households in 1935, but that this figure had dropped to just over 60 percent by 1995. Living arrangements are thought to be important for elderly support across East Asia, including Cambodia (Zimmer and Kim, 2002), Thailand (Knodel and Debavalya, 1997), and Viet Nam (Anh et al, 1997). 
in rural areas, elders and adult children are typically in the same small group (a sub-village administrative unit) and live in close proximity with one another. Given increases in housing wealth accumulated in rural areas since the mid-1980s, the trend toward nuclear families may well signal a wealth effect independent of the traditional value of providing support and care to elder parents. A more important concern may be the proximity of adult children, and not whether they co-reside.

In Figure 1 of the paper, we present lowess plots (locally weighted regression lines) that summarize living arrangement by age cohort from the supplemental RCRE survey conducted in 2004. This summary information shows that co-residence with adult children was only around 60 percent among those aged 60 to 70, but that more than half the elderly living alone or with a spouse in this age range had adult children living in the village. This suggests that while co-residence was well below levels of the 1930s, adult children were still potentially available to provide care. As elder parent age increases, the probability of co-residence with an adult child approaches 100 percent. $^{5}$ In our first set of analyses on migration decisions, below, we make use of the existence of parents and their health status, regardless of presence in the household, to analyze the impact of parent health on migration behavior in models robust to the possibility that migration and the living arrangements of elderly parents are systematically related.

Analyses of the labor supply behavior of older adults have also been used to study the "retirement" behavior of China's rural residents. Agricultural production requires hard physical labor, and continued exacting labor may lead to injury, raise the possibility of developing health problems, or significantly reduce the well-being of older residents. Benjamin et al (2003) test the hypothesis that "retirement" patterns of elderly Chinese in rural areas can be characterized as a condition of "ceaseless toil" in which the elderly must work their entire lives because they lack the resources to retire. ${ }^{6}$ Collective ownership of land and col-

\footnotetext{
${ }^{5}$ Of course, two very different conclusions are consistent with evidence of greater incidence of co-residence with age in a simple cross-section: the oldest, who are more likely to be infirm, tend to move in with adult children; alternatively, if co-residence does have an impact on the level of care-giving, then perhaps only the elderly living with adult children reach old age.

${ }^{6}$ The expression "ceaseless toil" was first coined by Deborah Davis-Friedman (1991) as a description of retirement patterns in pre-reform China.
} 
lective production during their youth mean that current generations of elderly (and older middle-aged farmers) were unable to accumulate assets that could provide funds capable of facilitating retirement. Benjamin et al (2003) find that those rural residents with more wealth show steeper declines in days of labor supplied after age 55, suggesting that lack of tradable assets or liquid wealth may indeed limit the ability of elderly residents to retire.

\section{Rural-Urban Migration in China}

During the 1990s, China's labor market experienced dramatic growth in the volume of rural migrants moving to urban areas for employment. Estimates using the one percent sample from the 1990 and 2000 rounds of the Population Census and the 1995 one percent population survey show that the inter-county migrant population grew from just over 20 million in 1990 to 45 million in 1995 and 79 million by 2000 (Liang and Ma, 2004). Surveys conducted by the National Bureau of Statistics (NBS) and the Ministry of Agriculture include more detailed retrospective information on past short-term migration, and suggest even higher levels of labor migration than those reported in the census (Cai, Park and Zhao, 2006).

Before labor mobility restrictions were relaxed, households in remote regions of rural China faced low returns to local economic activity, raising the possibility that they were stuck in geographic poverty traps (Jalan and Ravallion, 2002). A considerable body of evidence suggests that the growth and scale of rural migrant flows in China make migrant opportunity an important mechanism for poverty reduction in China. Studies of the impact of migration on source communities demonstrate that opportunities to migrate are contributing to growth in rural incomes (Taylor, Rozelle and de Brauw, 2003), easing problems of risk-coping and risk-management (Du, Park and Wang, 2005; Giles, 2005; Giles and Yoo, 2005), and possibly leading to higher levels of local investment in productive activities (Zhao, 2002).

With respect to well-being of the elderly, however, it is likely that the decision of adult children to participate in migrant labor markets places greater pressure on the rural elderly to continue working. Given that rural households do not own the land that they farm, and that land transfer rights are still not well-defined in many regions, taking land out of production may lead to both lost income and risk that land will be transferred to another 
family. Thus, lack of a pension system for the rural elderly is compounded by a system of land ownership that leaves them with few sources of non-labor income in their retirement. Furthermore, given the returns to migrant employment, it is likely that healthy farmers over 55 years of age, who lack the resources to retire, choose to continue work in agriculture in order to allow adult children to increase family income through employment outside the village.

Once elders become infirm, however, it is likely that adult children will find a way to provide some type of care. Often this will mean that at least one adult child will either return to the village, or decide not to participate in the migrant labor market. Anecdotal accounts suggest that migrants face pressure to return to the countryside to fulfill obligations of providing care once parents are too ill to care for themselves. ${ }^{7}$ The potential opportunity cost of caring for elder parents is clear, however, from descriptive evidence on conflict among siblings over decisions related to elder care. In 11 of the $55 \mathrm{RCRE}$ villages from which household survey data are drawn for this paper, village leaders reported such disputes were either the first or second most important cause of conflict within the village. ${ }^{8}$ As we will see below, the presence of siblings reduces the impact of poor elder parent health on migration decisions. But it is also likely that siblings "bargaining" over who will meet their traditional responsibility clearly recognize the opportunity costs of caring for parents.

In Figure S.3, we summarize the migrant labor market participation of registered residents from RCRE households in 2003. A migrant is defined as someone who has formal legal residence in an RCRE household, but is working and living outside the home county for more than six months of the year. Two characteristics of rural-urban migrants are evident in Figure S.3: first, men participate in the migrant labor market at higher rates than women for any age cohort, and second, most migrants are relatively young. In our analysis below, we look at the migration decision of men and women separately, and concentrate on decisions

\footnotetext{
${ }^{7}$ Pang et al (2004), for example, cite an interview with a couple who stated that they had to return to their home village from higher wage jobs as migrants to care for an elderly parent.

${ }^{8}$ Conflict among siblings over care for the elderly was the third most important source of conflict in the 55 RCRE villages from which our data are drawn. This places conflict over elder care just behind disputes over land boundaries and water rights, which are common across the developing world. The Chinese term we used for conflict in the survey, jiufen, implies a dispute significant enough to bring in police or other authorities from outside the village.
} 
made by individuals between 16 and 40 years of age.

\section{THEORETICAL FRAMEWORK: EXPANDED TECHNICAL EXPOSITION}

\section{Parent Health and Adult Child Utility}

We assume that adult children have altruistic preferences, such that the utility of an adult child, $U$, is a function of own consumption and the well-being of elderly parents, $U^{P}$ :

$$
U\left(c, l, \mathbf{Z}, U^{P}\left(H^{P}\right)\right)
$$

where $c$ is a consumption good, $l$ is leisure, $\mathbf{Z}$ is a vector of taste shifters. ${ }^{9}$ Parent utility, in turn, is a function of own health, $H^{P}$, which can be represented by the health production function:

$$
H^{P}=H\left(\alpha, h, t\left(t^{c}, t^{s}, t^{o}\right), I\right)
$$

such that parent health is a function of time put into care, $t$, a health technology parameter, $\alpha$, exogenous health status, $h$, and income transferred from children or other sources, $I$. Exogenous health status, $h$, will take on a value of one if, conditional on age, the parent is in good health and does not require assistance preparing food, maintaining a household, or performing other important activities of daily life. If the adult parent falls ill or is in bad health, exogenous health equals zero. We assume that time spent caring for an adult parent, $t$, could be provided by the adult child, $t^{c}$, by siblings, $t^{s}$, or by others, $t^{o}$. Controlling for the health technology parameter and income, we present our assumptions about the relationship between parent utility and care provided, $t$, in a "reduced form" representation shown in Figure S.4. We normalize parent well-being for the case of exogenous good health to be $U(1,)=$.1 . When parent exogenous health is bad, parent utility $U(0, t)$ increases from a minimum level, $a$, at a diminishing rate with increases in the amount of time spent providing care, $t$. Achievable parent utility when parent health is bad will not be as high as when

\footnotetext{
${ }^{9}$ One could imagine more complicated models of parent utility that would allow for transfers and exchange of services between parents and adult children based on a mix of exchange and altruistic movites. For ease of exposition, we use a simple model in which the dimension of along which parent utility affects decision of adult children relates to well-being when ill.
} 
exogenous health is good, but will converge to some level, $b<1$, with increasing time spent on the provision of care.

Adult children face a budget constraint (3) in which hired care provided to parents from siblings, at price $P_{s}$, and from others, at price $P_{o}$, plus income transferred to parents, and expenditures on consumption goods must equal income that could be earned either locally or in the migrant market.

$$
\begin{aligned}
P_{s} t^{s}+P_{o} t^{o}+I^{c}+P_{c} c & =P_{a} f\left(t^{f}, A\right)+\left(t^{l o c}-t^{c}\right) w^{l o c} \\
& +\left(t^{m i g} w^{m i g}-M\right)\left(t^{m i g} w^{m i g} \geq M\right)
\end{aligned}
$$

Individuals have a fixed time endowment, $T$, such that

$$
T=l+t^{c}+t^{f}+t^{l o c}+t^{m i g}
$$

and make choices over consumption, $c$, income transfers to parents, $I^{c}$, and allocation of time to leisure, $l$, to providing care for elders, $t^{c}$, to farm production, $t^{f}$, to local wage employment, $t^{l o c}$, and to employment in the migrant labor market, $t^{m i g}$. Income from agricultural production is earned from selling an agricultural commodity at price $P_{a}$ and produced with labor and land inputs, $t^{f}$ and $A$, with a standard production function $f\left(t^{f}, A\right)$. The opportunity cost of providing care is valued at the local wage rate, $w^{l o c}$, but the opportunity cost may be considerably higher if providing care makes it impossible for employment in the migrant labor market, at wage $w^{\text {mig }}$, to be of sufficient duration to compensate for fixed migration costs, $M$. In this case, the adult child will forgo employment in the migrant labor market all together.

\section{Parent Health and Participation in the Migrant Labor Market}

The adult child's decision can be represented in terms of indirect utility function of exogenous parameters:

$$
V\left(P_{s}, P_{o}, P_{c}, w^{*}, h, \mathbf{Z}, \alpha\right)
$$


The decision to migrate can be understood by looking at whether $V$ increases or decreases with participation in the migrant labor market and how exogenous health status, $h$, and presence of siblings in the village may influence this decision. We treat $w^{*}$ as the net wage (or returns) that may be earned through employment in the migrant market net of the costs of migrating and the opportunity cost wages or farm profits in the home village. ${ }^{10}$ We totally differentiate (4) and examine how utility will change with migration in each case.

Case 1: Elderly parent is healthy and the adult child has siblings $(h=1, s>0)$. In this case,

$$
d V^{1}=\frac{\partial V}{\partial P_{c}} \partial P_{c}+\frac{\partial V}{\partial w^{*}} \partial w^{*}
$$

change in utility with migration is influenced primarily by the higher prices of consumption goods in urban areas, and by the net increase in earnings available through migration. It should be straightforward to observe that $\frac{\partial V}{\partial P_{c}} \partial P_{c}<0$ and $\frac{\partial V}{\partial w^{*}} \partial w^{*}>0$ when expected wages are sufficiently high in urban areas. Since time spent providing care to elderly parents has no impact on parent utility when parents are healthy, $t^{o}=0$ and $t^{s}=0$, and the cost of hiring individuals to provide care does not enter into the potential migrant's decision.

Case 2: Elderly parent is ill and the adult child has siblings $(h=0, s>0)$. Change in utility with migration will now be influenced by the "cost of hiring" siblings to care for the elderly parent, $P_{s}$.

$$
d V^{2}=\frac{\partial V}{\partial P_{s}} \partial P_{s}+\frac{\partial V}{\partial P_{c}} \partial P_{c}+\frac{\partial V}{\partial w^{*}} \partial w^{*}
$$

In this case, we assume that $t^{s} \neq 0$ and $t^{o}=0$ as sibling assistance in caring for the elderly will cost less and be of higher quality than hiring a non-family member to provide care. Nonetheless, whether payment is in financial terms, in-kind, through the promise of unspecified future assistance, or extracted in some other way in the family relationship (e.g., through guilt), we assume that care provided by a sibling to an elder is not "free".

\footnotetext{
${ }^{10}$ Of course this net wage premium will not be directly observed, but will be determined by observables related to land holdings, family wealth and village characteristics that affect returns to local activity, and by human capital and other dimensions of ability that determine wages which an individual may earn in the migrant labor market.
} 
Case 3: Elderly parent is healthy and the adult child does not have siblings $(h=1, s=0)$. As the elderly parent will not require care, change in utility from migrating will be identical to the change under Case 1 , or

$$
d V^{3}=\frac{\partial V}{\partial P_{c}} \partial P_{c}+\frac{\partial V}{\partial w^{*}} \partial w^{*}
$$

Case 4: Elderly parent is ill and the adult child does not have siblings $(h=0, s=0)$. In this case, provision of care to the elderly parent will require hiring a non-family member if the adult child is employed as a migrant, so the change in indirect utility will be

$$
d V^{4}=\frac{\partial V}{\partial P_{o}} \partial P_{o}+\frac{\partial V}{\partial P_{c}} \partial P_{c}+\frac{\partial V}{\partial w^{*}} \partial w^{*}
$$

Hiring someone other than a family member will be costly, and in some cases the cost will be so high that we do not observe such transactions.

Making the reasonable assumption that $\frac{\partial V}{\partial P_{o}} \partial P_{o}<\frac{\partial V}{\partial P_{s}} \partial P_{s}<0$ leads us to conclude that $d V^{4}<d V^{2}<d V^{1}, d V^{3}$, or, that participating in the migrant labor market will look less attractive if the individual has an elderly parent who is not in good health. Further, if the individual has no siblings available to act as potential caregivers, then choosing to participate in the migrant labor market will be even less attractive when a parent is in poor health.

\section{REFERENCES}

Anderson, Kathryn H. and Richard V. Burkhauser. 1985. "The Retirement-Health Nexus: A New Measure of an Old Puzzle," Journal of Human Resources v20, n3 (Summer 1985): 315-30.

Anh, Truong Si, Bui The Cuong, Daniel Goodkind, and John Knodel. 1997. "Living Arrangements, Patrilinearity and Sources of Support among Elderly Vietnamese," Asia-Pacific Population Journal 12(4): 69-88.

Benjamin, Dwayne, Loren Brandt and Jia-Zheung Fan. 2003. "Health and Labor Supply of the Elderly in Rural China," manuscript, Department of Economics, University of Toronto

Benjamin, Dwayne, Loren Brandt and Scott Rozelle. 2000. "Aging, Well-Being and Social Security in Rural North China," Population and Development Review, Vol 26: 89-116. 
Bian, Fuqin, John R. Logan and Yanjie Bian. 1998. "Intergenerational Relations in Urban China: Proximity, Contact and Help to Parents," Demography, 35(1): 115-124.

Cai, Fang, John Giles and Xin Meng. 2006. "How Well Do Children Insure Parents Against Low Retirement Income? An Analysis Using Survey Data from Urban China," Journal of Public Economics (in press).

Cai, Fang, Albert Park and Yaohui Zhao. 2006. "The Chinese Labor Market," chapter prepared for China's Economic Transition: Origins, Mechanisms and Consequences (Loren Brandt and Thomas Rawski, editors.), mimeograph, University of Michigan.

Cameron, Lisa and Deborah Cobb-Clark. 2001. "Old-Age Labour Supply in the Developing World," Applied Economics Letters v9, n10 (August 2002): 649-52.

Davis-Friedman, Deborah. 1991. Long lives: Chinese elderly and the communist revolution. Stanford: Stanford University Press.

Du, Yang, Albert Park and Sangui Wang (2005). "Migration and Rural Poverty in China" Journal of Comparative Economics 33(4): 688-709.

Fang, Yuan, Chuanbin Wang and Yuhua Song. 1992. "Support for the Elderly in China," in Family Support for the Elderly: The International Experience, Hal L. Kendig, Akiko Hashimoto, and Larry C. Copport (eds.). New York: Oxford University Press, pp. 250-259.

Giles, John (2005). "Is Life More Risky in the Open? Household Risk-Coping and the Opening of China's Labor Markets," Journal of Development Economics (forthcoming).

Giles, John and Kyeongwon Yoo (2005). "Precautionary Behavior, Migrant Networks and Household Consumption Decisions: An Empirical Analysis Using Household Panel Data from Rural China," Department of Economics, Michigan State University, mimeo.

Jalan, Jyotsna and Martin Ravallion. 2002. "Geographic Poverty Traps? A Micro Model of Consumption Growth in Rural China," Journal of Applied Econometrics 17(4): 329-46.

Knodel, John and Napaporn Chayovan. 1997. "Family Support and Living Arrangements of Thai elderly," Asia-Pacific Population Journal 12(4): 51-68.

Lee, Yean-Ju and Zhenyu Xiao. 1998. "Children's Support for Elderly Parents in Urban and Rural China: Results from a National Survey," Journal of Cross-Cultural Gerontology 13: $39-62$.

Liang, Zai and Zhongdong Ma. 2004. "China's Floating Population: New Evidence from the 2000 Census," Population and Development Review 30(3): 467-488.

Lin, Jiang. 1994. "Parity and Security: A Simulation Study of Old-Age Support in Rural China," Population and Development Review 20: 423-48. 
Pang, Lihua, Alan de Brauw, and Scott Rozelle. 2004. "Working Until You Drop: The Elderly of Rural China," China Journal 52, July 2004, 73-96.

Selden, Mark. 1993. "Family Strategies and Structures in Rural North China," in Chinese Families in the Post-Mao Era, eds. Deborah Davis and Stevan Harrell. Berkeley: University of California Press, pp. 139-164.

Taylor, J. Edward, Scott Rozelle, and Alan de Brauw. 2003. "Migration and Incomes in Source Communities: A New Economics of Migration Perspective from China," Economic Development and Cultural Change, 52(1), 75-101.

World Bank. 1994. Averting the Old Age Crisis. New York: Oxford University Press for the World Bank.

Zhao, Yaohui. 2002. "Causes and Consequences of Return Migration: Recent Evidence from China," Journal of Comparative Economics v30, n2 (June 2002): 376-94.

Zimmer, Zachary and Sovan Kiry Kim. 2002. "Living Arrangements and Socio-Demographic Conditions of Older Adults in Cambodia," Population Council Working Paper, No. 157.

Zimmer, Zachary and Julia Kwong. 2003. "Family Size and Support of Older Adults in Urban and Rural China: Current Effects and Future Implications," Demography, Volume 40(1): 23-44. 
Figure S.1. The Evolution of China's Population Pyramid Over Time
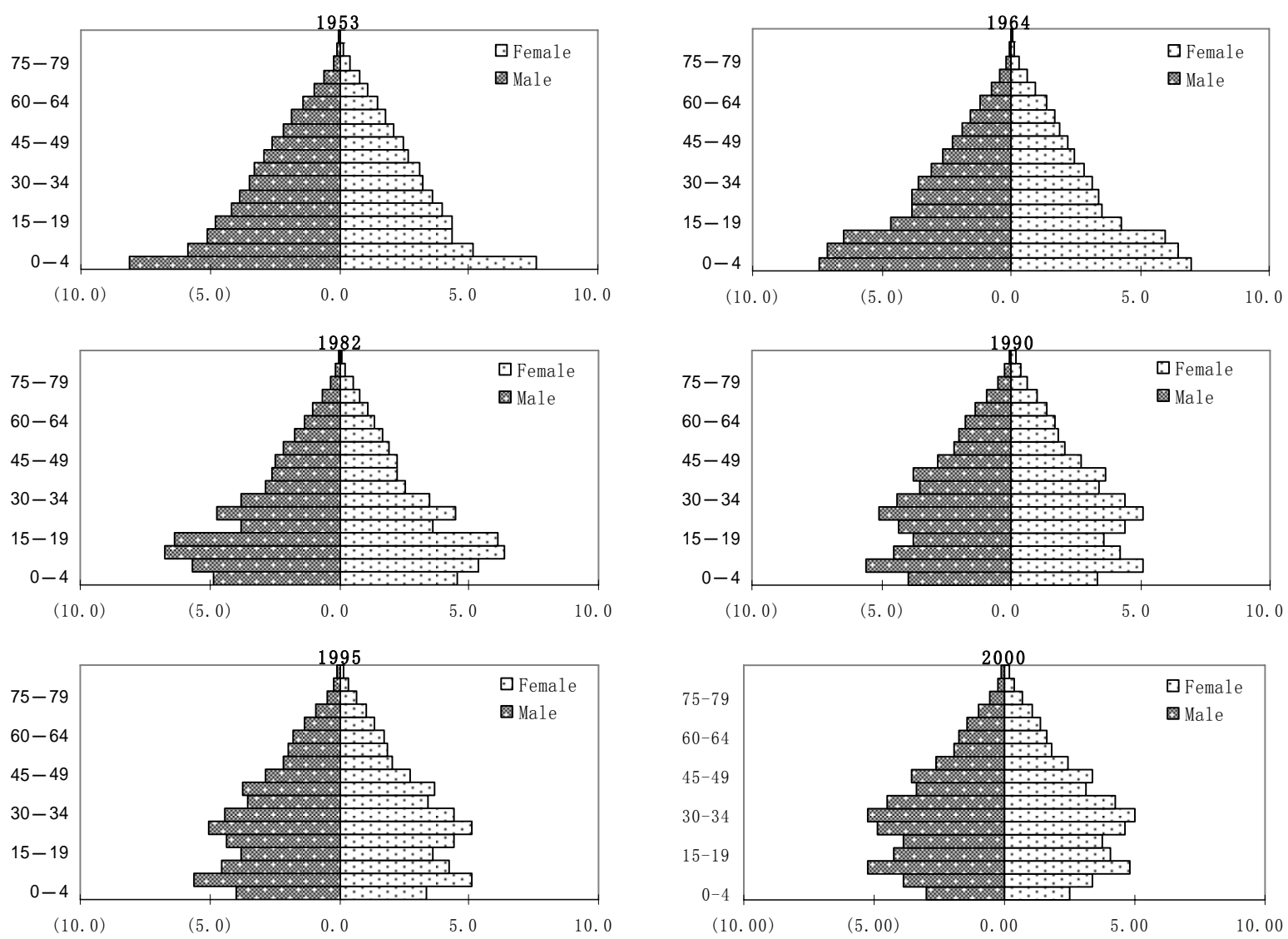

Notes: Source data is from China Population Census, and 1 Percent Population Census (Various Years). Each bar shows the percentage of the total population represented by the demographic group represented. 
Figure S.2. Living Arrangements of China's Elderly (CHNS)

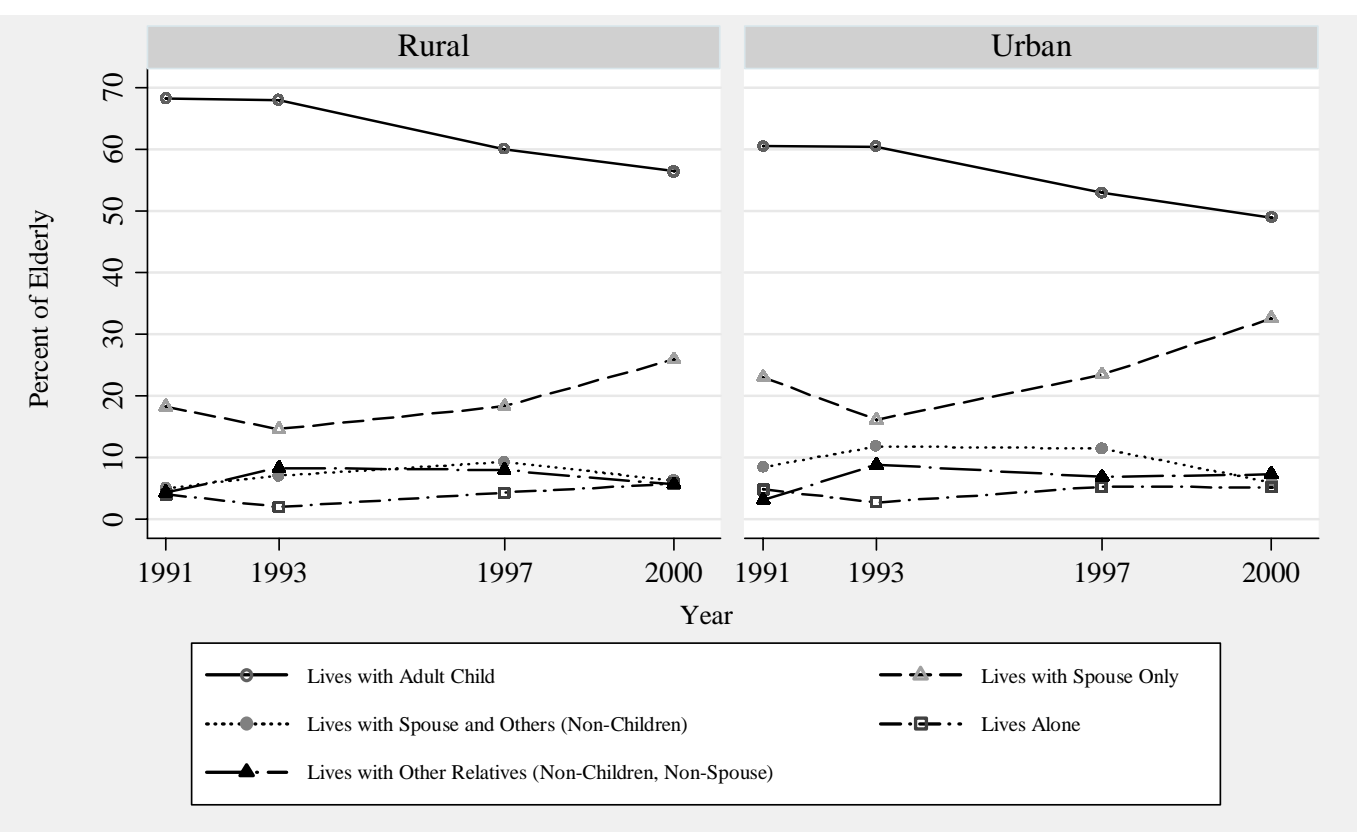

Notes: Information on living arrangements are taken from the 1991, 1993, 1997 and 2000 rounds of the China Health and Nutrition Survey (CHNS). 
Figure S.3. Migration Rate from RCRE Villages in 2003, By Age Cohort

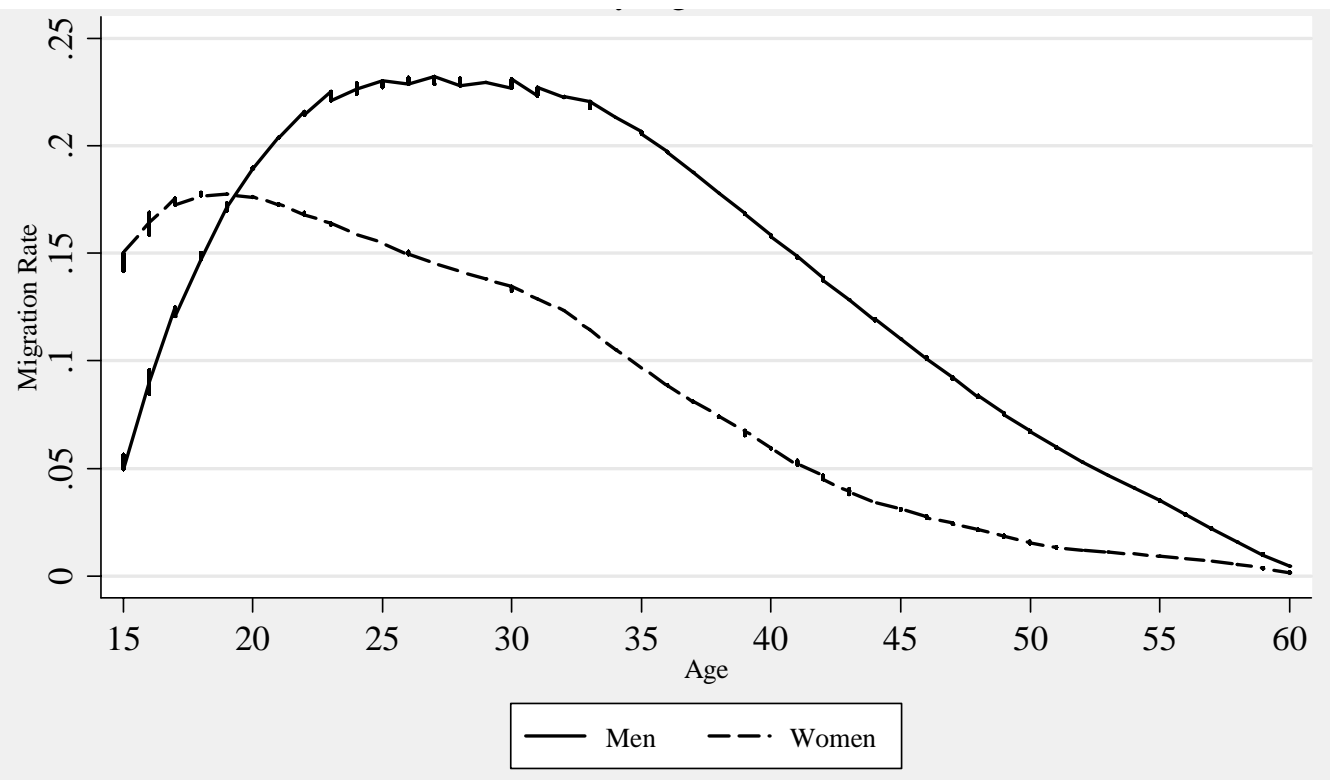

Notes: Data are drawn from the RCRE 2004 Supplemental Survey and reflect the migration status of current and former residents of RCRE households from Anhui, Henan, Jiangsu and Shanxi provinces. 
Figure S.4. Care Provided and Elderly Well-Being

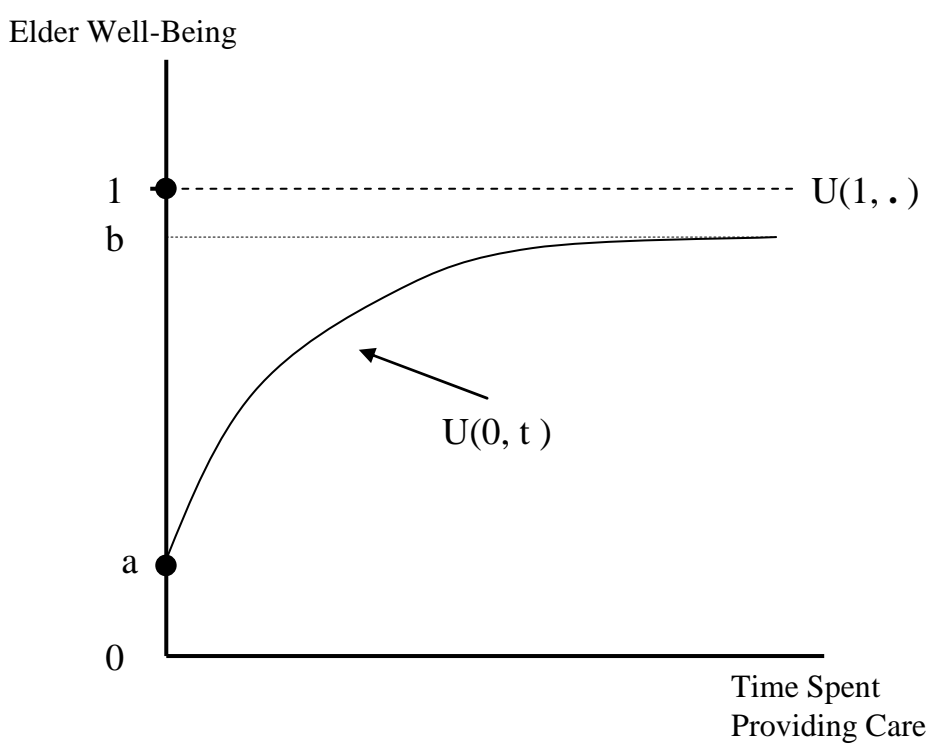


Figure S.5. BMI and the Self-Reported Health Status of the Elderly in Rural China (CHNS)

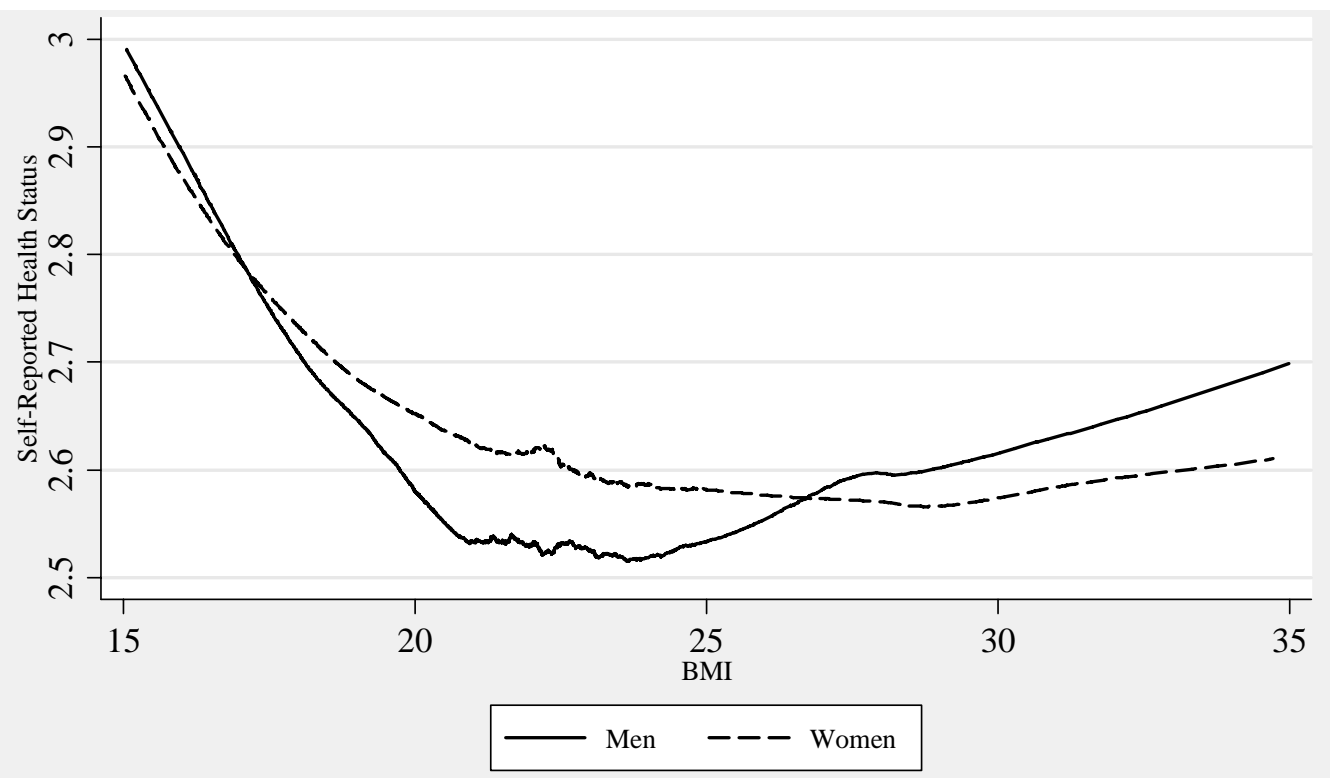

Notes: Data are drawn from the rural sub-sample of the China Health and Nutrition Survey for survey years 1991, 1993, 1997 and 2000. Lowess plots are shown for individuals over age 60 in the year of observation. 


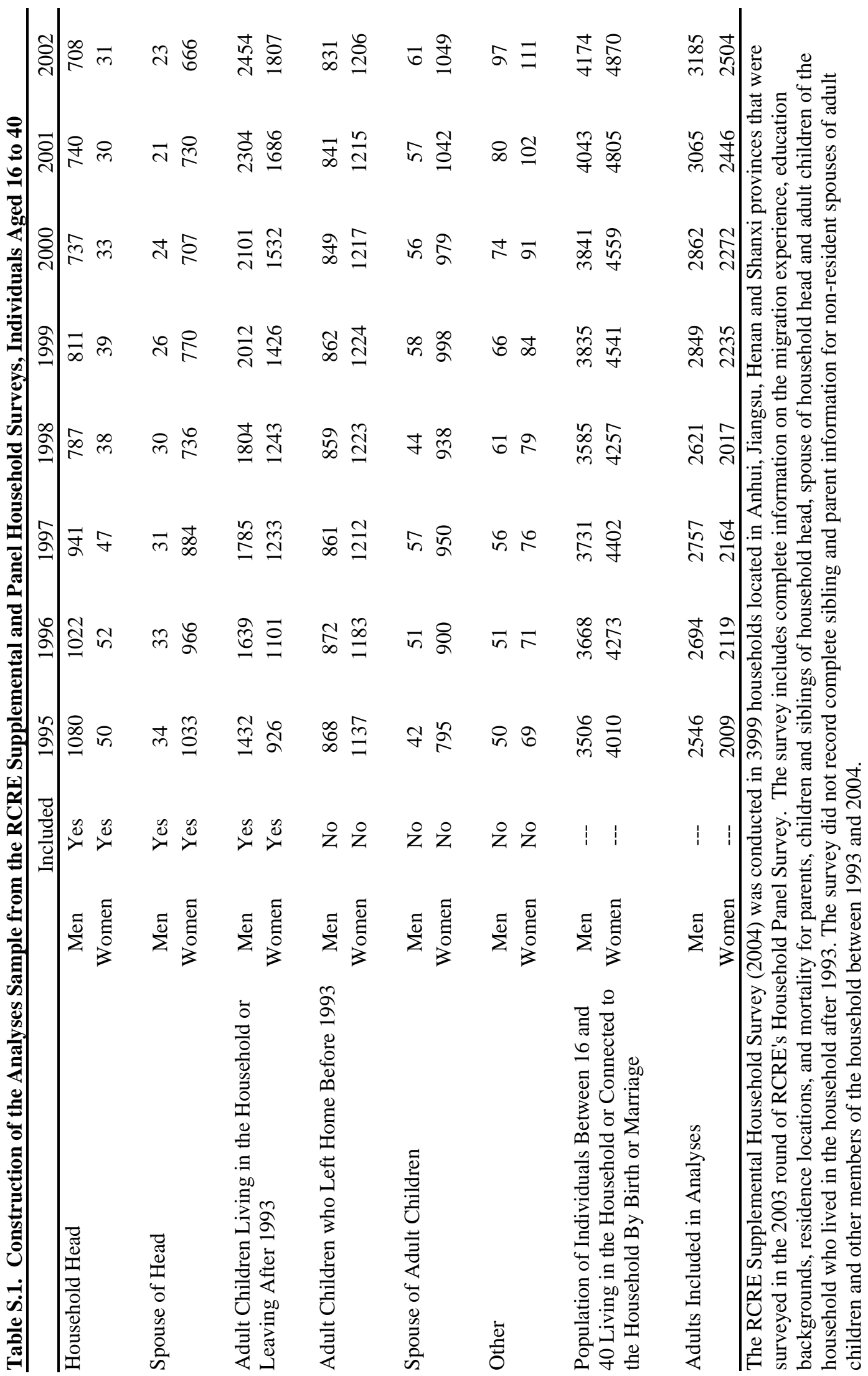




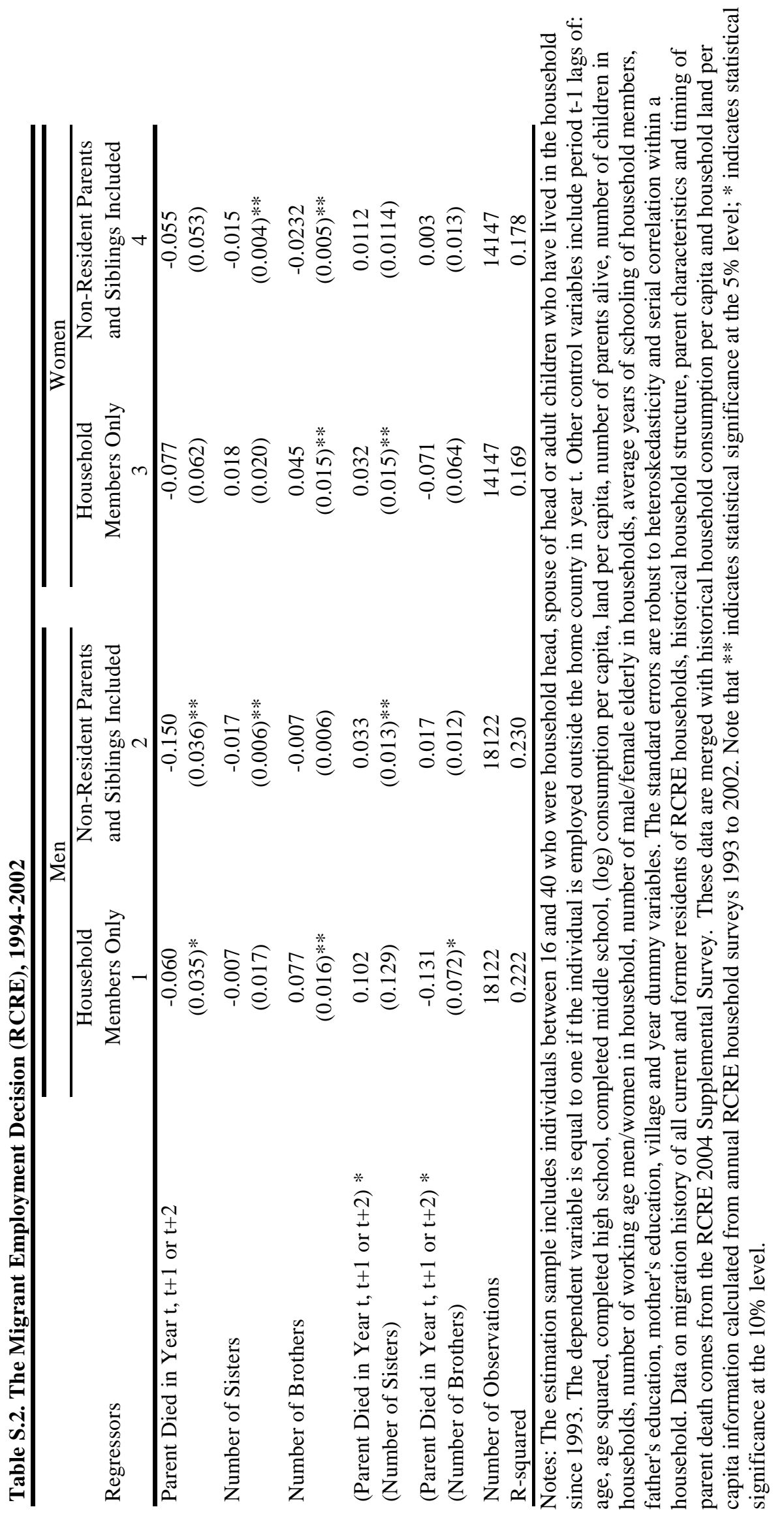

